NBER WORKING PAPER SERIES

\title{
HAVE EMPLOYMENT REDUCTIONS \\ BECOME GOOD NEWS FOR \\ SHAREHOLDERS? THE EFFECT OF \\ JOB LOSS ANNOUNCEMENTS ON \\ STOCK PRICES, 1970-97
}

\author{
Henry S. Farber \\ Kevin F. Hallock \\ Working Paper 7295 \\ http://www.nber.org/papers/w7295
}

NATIONAL BUREAU OF ECONOMIC RESEARCH

1050 Massachusetts Avenue

Cambridge, MA 02138

August 1999

The views expressed herein are those of the authors and not necessarily those of the National Bureau of Economic Research.

(C) 1999 by Henry S. Farber and Kevin F. Hallock. All rights reserved. Short sections of text, not to exceed 
two paragraphs, may be quoted without explicit permission provided that full credit, including $\odot$ notice, is given to the source.

Have Employment Reductions Become Good News

for Shareholders? The Effect of Job Loss

Announcements on Stock Prices, 1970 - 97

Henry S. Farber and Kevin F. Hallock

NBER Working Paper No. 7295

August 1999

JEL No. G14, J63

\section{ABSTRACT}

We study the reaction of stock prices to announcements of reductions in force (RIFs) using a sample of nearly 3878 such announcements in 1176 large firms during the 1970-97 period collected from the Wall Street Journal Index. We note that, although there has been a dramatic secular increase in news stories related to job loss, the total number of actual announcements fro the firms in our sample follows the business cycle quite closely. We then examine changes over time in standard summary statistics (means, meridians, fraction negative) of the distribution of stock market reactions as well as changes over time in kernel density estimates of this distribution. We find clear evidence that the distribution of stock market reactions has shifted to the right (became less negative) over time. One possible explanation for this change is that, over the last three decades, RIFs designed to improve efficiency have become more common relative to RIFs designed to cope with reductions in product demand. We find that, although this explanation shows some promise, most of the decline in the negative stock price reaction remains unexplained.

\author{
Henry S. Farber \\ Industrial Relations Section \\ Firestone Library \\ Princeton University \\ Princeton, NJ 08544 \\ and NBER \\ farber@princeton.edu
}

Kevin F. Hallock

Department of Economics

College of Commerce \& Business Admin.

University of Illinois

1206 South Sixth Street

Champaign, IL 61820

hallock@uiuc.edu 


\title{
Have Employment Reductions Become Good News for Shareholders? The Effect of Job Loss Announcements on Stock Prices, 1970-97
}

\author{
Henry S. Farber and Kevin F. Hallock
}

\section{Introduction}

There has been substantial discussion in the business press and elsewhere recently about the effects of "downsizing" on firms, workers, and families. In fact there has been an explosion in the number of newspaper articles written about job loss, reductions in force, layoffs and the like in the past decade (see figure 1). ${ }^{1}$ While the effects of job loss on workers are clearly negative (see, for example, Farber, 1997), there have been suggestions in the business press and by policy groups that owners of firms profit handsomely as stock prices increase around the time of job loss announcements (Anderson and Cavanagh, 1994, and Sloan, 1996). These suggestions persist despite a growing body of empirical work that finds fairly consistent negative reactions of stock prices to announcements of reductions in the labor force (RIFs).

A straightforward interpretation of a negative relationship between announcements of RIFs and stock prices is that the RIFs signal a reduction in product demand relative to existing production capacity. It is more difficult to understand why stock prices might respond positively to announcements of RIFs. One interpretation that resonates with much of the recent attention paid to corporate "downsizing" and "restructuring" is that announcements of RIFs might signal that management has found more efficient ways to

We thank Yacine Ait-Sahalia, Orley Ashenfelter, Marianne Bertrand, Ken Chay, Martin Conyon, Erica Groshen, Casey Ichniowski, Jeff Kling, Stacey Kole, Alan Krueger, David Lee, David Levine, participants in the Princeton Labor Lunch group, those attending our presentation at the 1999 meeting of the Industrial Relations Research Association, and at seminars at BYU, CIRANO, the NBER, Texas A \& M, and UCLA/RAND. We are grateful to Michelle Arthur, Sherrilyn Billger, John Deke, Erica Field, and Kristin Stanton for excellent research assistance. The Institute of Labor and Industrial Relations at the University of Illinois and the Industrial Relations Section at Princeton University provided financial support.

1 Figure 1 is a plot of the number of articles in the Wall Street Journal collected from Pro Quest's Newspaper Abstracts that included the following set of words: layoff, laid off, downsize, downsizing, or plant closing for 1985-1995 period. We do not use these data or this method for collecting our data elsewhere in the paper. Note that it is not the case that the higher level of news stories about job loss in the 1990s simply reflects a higher number of announcements by firms. This is clear from the time series of the frequency of job loss announcements shown in figure 2 and described in section 3. 
produce using less (or cheaper) labor. ${ }^{2}$ To the extent that "efficiency" RIFs have become more common relative to "deficient demand" RIFs over the last three decades, we would expect that the average relationship between announcements of RIFs and stock prices would have become less negative (or even positive) over time.

In order to address this issue, we used the Wall Street Journal Index to create as complete a list as possible of announcements of RIFs by every firm that was ever listed in the Fortune 500 for each of the 28 years from 1970 though 1997. We collected data on 3878 RIFs. This is about three times more than examined in any previous study, and the 28 years are roughly four times more than any previous work. ${ }^{3}$ These data offer us the opportunity to investigate whether and, to some extent, why there has been a changing relationship between share prices and announced RIFs over time.

We find some evidence that the stock market reaction to announcements of RIFs has, in fact, changed. The average share price reaction was most negative in the early part of the period covered, and the average reaction has become less negative in more recent years. We estimate the averge share price reaction over the entire 1970-1997 period to be -0.375 percent (s.e. $=0.06$ ). Broken down by decade, the average reaction was -0.647 (s.e. $=$ 0.10 ) in the $1970 \mathrm{~s},-0.261$ (s.e. $=0.10$ ) in the $1980 \mathrm{~s}$, and -0.112 (s.e. $=0.11$ ) in the 1990 s. We go on to consider whether the mix of reasons for the announced RIFs, the industry makeup or other RIF characteristics have changed over time and whether any of these have any explanatory power in describing the changing trend. We find that although some of these show promise in helping to explain the less negative relationship between share prices and announced RIFs over time, a complete explanation awaits further research.

\section{Data}

Our data come from three distinct sources. The first is a comprehensive set of information collected from the Wall Street Journal Index of every announcement we could find

2 See, for example, Dial and Murphy (1995) who present an interesting intensive case study of restructuring at General Dynamics in the early 1990s. They argue that the restructuring, which included RIFs, resulted in efficiency improvements and value creation.

3 Jacoby (1994) discusses downsizing in the context of a view of "welfare capitalism" from an historical point of view over the last century. 
of a job loss in each firm that ever existed in the Fortune 500 over a period of 28 years beginning in 1970. We collect accounting data from Standard and Poor's COMPUSTAT and daily stock return data from the Center for Research in Security Prices (CRSP) at the University of Chicago.

We created our job loss announcement sample by identifying each firm that ever existed in the Fortune 500 from 1970-1997. This left us with a list of 1703 different firm names over the 28 years. For each year, we then searched through the abstracts of each Wall Street Journal Index by company name for any announcement of a RIF. When an example was found, we recorded the date of the announcement as well as several other pieces of information where available. A unique feature of our data is the unusually long time period. We searched the paper index because, at the time the data were collected, no electronic source would allow us to search as far back as 1970 and we wanted to use a consistent sample throughout the entire time period. Our tabulations of announcements of RIFs compare favorably with Hallock (1998) who has completed the largest previous study (using data from 1987-1995) using data from an electronic source.

There are some potential problems in using data collected from a source such as the Wall Street Journal (see Thompson, Olsen, and Dietrich, 1987). For example, it may not be the case either that all RIFs are announced in the Wall Street Journal or that the Journal chooses to report all events. But we believe that most events are reported in the Wall Street Journal. This is because the original sample consists of firms that are among the largest in the United States, so it makes sense that the Wall Street Journal would report news of even quite small events involving these firms. Evidence for this is that there are many instances of very small events reported. In addition, we are primarily interested in investigating the share price reaction to announced RIFs, and RIFs that are not announced are less likely to have substantial effects on share prices.

We recorded 17 different reasons for the announced RIFs (described in more detail below) and were able to identify reasons for 75 percent of the observations. We also know the number of workers planned to be let go as part of the RIF for 31 percent of the announcements. While the mean number of workers announced was 2349 (standard deviation of 4352), the median number of workers let go was 900 . Finally, we recorded 
whether the job loss was temporary or permanent for 33 percent of the announcements, and, among these, 29 percent were temporary. For 28 percent of the RIFs, we were also able to identify whether the RIF involved a foreign subsidiary. Of these, only 12 percent were foreign.

In order to measure the stock price reaction, we used daily stock returns for each firm for each day in the sample. These data are collected by the Center for Research in Security Prices (CRSP) at the University of Chicago. Obviously, we needed to match our firm names as reported in Fortune with unique security identifiers used in CRSP. There was no information in the CRSP data for 146 of the 1703 firm names from our Fortune 500 list, probably because they were not publicly traded. Of the 1557 unique firm names that were left over, 198 were identified with multiple securities and were dropped from this analysis. Of the 1359 "unique" firm names that remained, 183 names were identified with the same firm as another with either a similar (or in some cases quite different) name. ${ }^{4}$ This left us with 1176 unique firms over the 28 years from 1970-1997 for which we have valid stock data for at least some years. We were able to identify 3878 job loss announcements that had matched stock return data for the relevant periods.

Finally, we collected information on annual accounting and related data from Standard and Poor's COMPUSTAT. These data include the industry, market value, assets, sales, and number of employees. In table 1, we display some descriptive information from the COMPUSTAT data, on firm value, assets, sales, and number of employees. The financial data are all reported in thousands of dollars (both nominal and real (1997) dollars). It is clear, given the information in table 1 and the sample frame, that these include the largest firms in the United States. The median firm in the sample has roughly 43,000 employees.

\section{Frequency of Job Loss Announcements}

The number of RIFs announced by firms in our sample varies substantially across the years we study in ways that, not surprisingly, closely follow the state of the labor market. Figure 2 displays the number of RIFs in our sample by year along with the

\footnotetext{
4 For example Freeport Sulfur is the same as Freeport Minerals, Hoover Universal is the same as Hoover Ball and Bearing, and Standard Oil of California is the same as Chevron.
} 
civilian unemployment rate. The number of announcements varied from a minimum of 48 in 1997 (a year of very low unemployment) to a maximum of 285 in 1982 (a year of very high unemployment). Overall, the mean number of announcements per year was 139 with a standard deviation of 64 . The simple correlation between the number of announcements and the civilian unemployment rate (Council of Economic Advisors, 1998) over the 19701997 period was 0.58 . With the exception of the first two years in our sample (1970 and 1971) the time series of the number of RIF announcements per year follows the time series of the unemployment rate quite closely. ${ }^{5}$ The correlation from 1972-1997 (omitting 1970 and 1971) between the number of RIF announcements and the unemployment rate is 0.68 .

Farber (1997) reports "three-year rates of job loss" using data from seven Displaced Worker's Surveys (DWS). He documents a decline in the overall rate of job loss from 13.3 percent in 1981-83 to 9 percent in 1987-88 and then a continuous increase to 12.8 percent in 1991-93. These findings are largely consistent with ours. Interestingly, Farber (1997) shows that the job loss rates in the DWS increased again (to 15.1 percent) in the 1993-95 sample, while our measure of the fraction of firms with at least one job loss announcement fell in this latter period as did the unemployment rate. However, our tabulations from the most recently released DWS (February 1998) show a decrease in job loss to 12.0 percent in the 1995-97 period.

\section{The Event Study Method}

The event study method that we employ is widely used in the empirical corporate finance literature (Brown and Warner, 1985; Campbell, Lo, and MacKinlay, 1997, Fama, Fisher, Jensen, and Roll, 1969, and MacKinlay, 1997) and we will, therefore, only describe the very basic ideas here. We should note that clearly defining the event date is critical and is often very difficult. For example Card and Krueger (1995) study the effects of news about legislation concerning the minimum wage on firms that may employ minimum wage workers. They suggest that some events, such as when it was revealed that Labor Secretary Robert Reich unexpectedly suggested to President Clinton that the administration not

\footnotetext{
5 The unemployment rate in 1970 and 1971 was relatively low (averaging 5.4 percent) while the number of announcements in those two years was relatively high (averaging 193 per year).
} 
push for an (expected) increase in the minimum wage are more useful (i.e., generally unanticipated) events than others such as when President Bush (not unexpectedly )vetoed a minimum wage increase.

In our case, we assume that the market became aware of the RIF on the day it was reported in the Wall Street Journal or at a time very close to that day. However, it may be that the market knew of what we identify as the announced event at some time prior, and, to the extent that this is the case, our analysis will not capture the full effect of layoff announcements on stock prices.

Cumulative average excess returns are calculated, as described below, using valueweighted return data from the Center for Research in Security Prices (CRSP) at the University of Chicago. Let $t$ index time in trading days, let $s$ indicate the "event date" (the date of the RIF announcement), and let $i$ index firms. First, the firm daily return, $R_{i t}$, is regressed on $R_{m t}$, the value weighted market index for date t, which is available from CRSP. This regression,

$$
R_{i t}=\alpha_{i}+\beta_{i} R_{m t}+\eta_{i t}
$$

is estimated for a period from day $s-60$ to day $s-30 .^{6} \mathrm{Next}$, for days around the event date, we calculate the daily abnormal, or excess, return, in the following way,

$$
E R_{i t}=R_{i t}-\left(\hat{\alpha_{i}}+\hat{\beta}_{i} R_{m t}\right)
$$

where $\hat{\alpha}_{i}$ and $\hat{\beta}_{i}$ are the estimated regression coefficients from equation (1). Intuitively, the excess return is the part of the movement in the stock return of firm $i$ that is not correlated with overall market movement in stock returns and presumably reflects unexpected firmspecific factors.

The excess returns calculated for each day around a RIF announcement are used to calculate the cumulative excess return for each announcement. These are computed by adding up the daily excess returns over various intervals called "event windows" around the date of the announcement.

\footnotetext{
${ }^{6}$ We tried various prediction periods such as -500 to -250 and -100 to -70 with no meaningful effect on the results.
} 
We report analyses based on cumulative excess returns computed using various intervals. Although we tend to focus on the three-day window (from day $s-1$ to day $s+1$ ), we also compute cumulative excess returns for a one day window (day $s$ alone) and an eleven-day window (from day $s-5$ to day $s+5$ ). As a useful summary of the data, we also compute the mean and median of the cumulative excess returns across all RIF announcements in each year for each of the three event windows. Finally, we compute the fraction of RIF announcements in each year with negative cumulative excess returns for each of the three event windows. If the announcements have no systematic effect on stock returns, then the mean and median cumulative excess return will not differ significantly from zero and the fraction negative will not differ significantly from 0.5 . If the announcements have a negative (positive) systematic effect on stock returns, then the mean and median cumulative excess return will be significantly negative (positive) and the fraction negative will be greater than (less than) 0.5 . The basic goals of our analysis are 1) to measure any systematic cumulative excess returns over these windows around job loss announcement dates, 2) to determine whether the stock price response to layoff announcements has changed over the period studied, and 3) to explain the patterns we find.

\section{Has the Market Reaction to RIF Announcements Changed Over Time?}

Our analysis is the first investigation that covers a sufficiently long time period (28 years) to provide meaningful facts on changes over time in the reaction of stock prices to the announcements of RIFs. While a large number of previous studies have investigated the simple relationship between announcements of RIFs and share price reactions using various time periods, none of these studies, use data earlier than 1979 and they use sample periods ranging from two to only nine years. The number of RIFs involved in each is also highly variable. In addition the focus of the previous papers was not always on a general set of announced RIFs from a sample of firms from the United States. For example, Abowd, Milkovich, and Hannon (1990) examined the share price reaction of a wide variety of announcements of human resource management practices, including employee compensation increases, health and safety violations, and permanent staff reductions. Blackwell, Marr, and Spivey (1990), and Kalra, Henderson, and Walker (1994) studied only plant 
closings. Gunderson, Verma, and Verma (1997) only examined Canadian Firms. Caves and Krepps (1993) were focused on manufacturing firms, and Hallock (1998) examined the relationship between Chief Executive Officer pay and announcements of worker reductions. The top panel of table 2 contains a brief review of some of these studies and reports point estimates of the average cumulative excess returns from the day prior to the day after the RIF announcement (the three-day event window). ${ }^{7}$ These studies show a relatively stable and small estimate of the share price reaction to RIF announcements of between - 0.05 and -1.29 percent, although two estimates, Caves and Krepps (-0.9 percent) and Datta and Iskandar-Datta (-1.3 percent) seem to be somewhat more negative than the others. The median estimate is -0.50 percent.

As a basis of comparison with the existing literature, the bottom panel of table 2 contains estimates based on our sample of the mean cumulative excess return in a threeday event window for the entire 1970-97 time period as well as for three sub-periods. The overall mean for the $1970-97$ period using our sample is -0.376 percent (s.e. $=0.06$ ), which is within the range of the existing estimates reported in the top panel of table 2 . The estimates by subperiod provide preliminary evidence that the mean cumulative excess returns in response to announcements of RIFs have become less negative over time. The subperiod means were -0.647 percent (s.e. $=0.10$ ) for the $1970-79$ period, -0.261 percent (s.e. $=0.10)$ for the $1980-89$ period, and -0.112 percent for the $1990-97$ period (s.e. $=$ $0.13) .^{8}$

In order to compare our estimates with the estimates derived by others, we have plotted in figure 3 , by year, the mean cumulative excess returns over a three day window using our data. In addition, we have graphically represented the results of the earlier studies ( $a-j$ from table 2) with dark solid lines. The horizontal span of the lines represents the years the previous studies covered and the vertical location represents the mean cumulative excess

\footnotetext{
7 In all but three studies from the previous literature we were able to identify the cumulative average excess return over the three day window.

8 The differences between the mean for the 1970-79 period and the means for the other two periods are statistically significant at conventional levels ( $p$-value $<0.004)$. The difference between the mean for the 1980-89 period and the 1990-97 period is not statistically significant at conventional levels ( $\mathrm{p}$-value = $0.182)$.
} 
returns over the three day window. ${ }^{9}$ Analogously, we have graphically represented the decadal averages of the cumulative excess returns computed from our data ( $k-m$ from table 2) with dotted lines. The estimates from the earlier literature are remarkably consistent with our own annual estimates. Given the relatively low mean cumulative return in 1990, even the two estimates which we identified as being somewhat below the others (Caves and Krepps, 1993, and Datta and Iskandar-Datta, 1996) seem consistent. This figure also makes clear that the periods covered by the earlier studies are concentrated in the 1980s, and, as a result, they cannot address the issue of changes over time in the stock market reaction to job loss announcements.

To investigate further the extent to which the share price reaction to RIF announcements has changed over time, figure 4 contains a series of plots which display the mean cumulative excess returns, the median cumulative excess returns, and the fraction negative cumulative excess returns by year over three event windows: 1) the day of the announcement, 2) from one day prior to one day after the announcement (three day interval), and 3) from five days prior to five days after the announcement (eleven day window). A linear time trend, fitted by OLS, is also included in each plot. The first row of the figure contains the plots for the one-day event window (the day of the RIF announcement) for each of the 28 years in the sample. The second row of the figure contains the analogous plots for the three-day event window (day -1 to day +1 ), and the third row of the figure contains those for the eleven-day event window (day -5 to day +5 ).

There does appear to be some evidence that market reaction to job loss announcements has changed over time, becoming less negative more recently. However, the strength of the relationship depends on the particular event window selected. While the slopes of the time trends in each of the figures suggest that the market reactions are becoming less negative, the strongest results are found for the three-day event window. As a crude test, OLS regressions of the annual values for the mean and median cumulative excess returns on a time trend yield significantly positive coefficients at standard levels for the three-day

\footnotetext{
9 For Datta and Iskandar-Datta (1996), and Karla, Henderson, and Walker (1994), this represents only a two day window and for Ursel and Armstrong-Stassen (1991), only a one day window.
} 
event window. ${ }^{10}$ Additionally, an OLS regression of the percent negative cumulative excess returns on a time trend yields a significant negative coefficient only for the three-day event window.

Hallock (1998) investigates the changing relationship between announced RIFs and stock prices using data from 1987 through 1995. He finds that "When examining average excess returns on the event date, there does not appear to be a particular pattern of more (or less) positive excess returns as time progresses through the data set. However, when examining larger event windows, the cumulative average excess returns are significantly positive in the last two years of the sample." This is not surprising if we look back to figure 3, which shows that 1994 and 1995 have the largest positive cumulative excess returns in our sample period.

\section{Investigating Heterogeneity with Kernel Density Estimates}

There is a substantial amount of heterogeneity across announcements in the stock price response, and this is not captured by the mean or median. The first panel of figure 5 a contains kernel density estimates of the distribution of cumulative excess returns by decade for the entire support of the distribution, but it is difficult to pick out systematic movements over time. In fact, there are some interesting movements in the center of the distribution that are masked by the scale of the graph. This is revealed in the second and third panels of figure $5 \mathrm{a}$, which focus on only the center of the distribution (from -0.2 to +0.2 and from -0.1 to +0.1 respectively). Focusing on the third panel, there is clearly more mass at moderate negative values in the 1970-79 period relative to later periods and more mass at positive values just above zero in the 1990-97 period relative to earlier periods.

More information about the changes in these distributions over time is contained in figure 5b. This figure contains plots of the three decadal differences (1980s - 1970s, 1990s - 1980s, and 1990s-1970s, respectively by column) in the estimated density functions and cumulative distribution functions (CDFs) of the cumulative excess returns. Negative values in these plots imply a smaller density or lower cumulative probability in the later period.

10 For the other windows we report on, only the time trend of the median cumulative excess return in the eleven-day window is statistically significant at conventional levels. 
Analogously, positive values in these plots imply a larger density or higher cumulative probability in the later period. These plots verify that there has been virtually no change in the distribution in the tails (outside the range from -0.1 percent to +0.1 percent). The differences in both the density functions and the CDFs are essentially zero in the tails regardless of the time periods being compared. Focusing on the center of the distributions, it is clear that there is more mass below zero in the earlier periods than in the later periods. The first panel in the first row of figure 5b shows that there was modest change between the 1970s and 1980s in the center with somewhat lower density in the 1980s than in the 1970s at small negative values and somewhat higher density at small positive values. The first panel in the second row shows that these changes in distribution translate into about a 2 percentage point lower probability of negative excess returns in the 1980s than in the 1970s. The direction of these movements remained the same and intensified between the the 1980s and 1990s. The second panel in each row in figure 5b contains the 1990s - 1980s differences, and these show about a 4 percentage point lower probability of negative excess returns in the 1990s than in the 1980s. The last panel in each row of the figure contains the 1990s - 1970s differences in the distributional measures, and they summarize the overall decline in density at slightly negative values over the longer period. There is about a 6 percentage point lower probability of negative excess returns in the 1990s than there was in the 1970s.

The changes in the cumulative distribution functions in the second row of figure $5 \mathrm{~b}$ allow us to make a fairly strong statement about movements in the distribution of cumulative excess returns over time. These differences are almost uniformly negative throughout the range. This implies that the distribution for later periods "almost" stochastically dominates the distribution for earlier periods. Essentially, the distribution of cumulative excess returns has moved to the right. ${ }^{11}$

\footnotetext{
11 It is clear from figure $5 \mathrm{~b}$ that it is not strictly true that the later distributions stochastically dominate the earlier distributions, and this is why we say "almost". But the deviations from stochastic dominance (positive values of the difference in CDFs) are minor.
} 


\section{What Accounts for the Decline in the Negative Share Price Reaction?}

Given that we have documented that the share price reaction to announcements of reductions in force is most negative early in our 28 year sample and has become less negative over time, we begin here by trying to explain this interesting change. To this end, we have collected data on possible reasons for the announcements, as well as firm characteristics such as industry and firm size. We begin by documenting trends in these characteristics over time and then turn to the relationship between these trends and the link between announcements of RIFs and stock prices.

\section{Can Changes in the Composition of RIF's account for the Trend?}

One plausible interpretation of the change in the relationship between announcements of RIFs and the stock price reaction is that the composition of RIFs has shifted away from "deficient-demand" RIFs (with negative information about the firm's prospects) and toward "efficiency" RIFs (with positive information about the firm's prospects). In order to investigate these possibilities we begin by documenting the time-series pattern of the distribution of reported reasons for the announcements of RIFs.

We were able to identify a reason for 2922 of the 3878 RIFs ( 75 percent). We must regard these reported reasons with caution, however. These are reasons as reported in the Wall Street Journal and, therefore, are subject to the interpretation of the author of the particular article and the view of the firm making the RIF as outlined in a press release. We originally collected 17 different reasons (see table 3 ) but consolidated them into only five categories: reorganization (13.59 percent), plant closing (33.88 percent), slump in demand (15.88 percent), cost issues (9.34 percent), and other (27.31 percent). ${ }^{12}$ While the demarcations are not sharp, one could view the plant closing and slump in demand categories to be deficient-demand and the reorganization and cost categories to be efficiency.

The relative frequencies of these categories varied substantially over the period studied. Figure 6 contains a series of plots of the fraction of all RIFs that are attributable to

12 The reorganization category includes reorganization, restructuring, merger, and in house merger. 
each of these five categories, as well as for the set for which reason is missing. Most striking perhaps, is that the fraction of RIFs associated with the reorganization category has increased dramatically and the fraction associated with plant closings has declined sharply. Those in the "cost issues" category have also increased by a relatively large amount. The "slump in demand" category has been quite variable and consistent with the business cycle (there are three peaks associated with each of the three recessions in the 1970s, 1980s, and 1990s).

The shift in the composition of RIF announcements away from the deficient-demand categories and toward the efficiency category has the potential to explain the decline in the magnitude of the negative average share price effect since 1970. A necessary condition for this explanation to be plausible is that it must be the case that average cumulative excess returns are more negative for deficient-demand RIFs than for efficiency RIFs. In order to investigate this directly, the first part of table 4 contains tabulations of the cumulative average cumulative excess returns over a three-day window (day -1 to day +1 ) by the announced reason. The four columns represent the various time periods: the entire sample (1970-97), the 1970s, the 1980s, and the 1990s.

The first row of the table reproduces the information from the bottom of table 2 and shows that the share price reaction to all announced RIFs has become less negative over time. The next panel breaks the RIFs down by reported reason categories. For the entire sample period three of the reasons have significantly negative excess returns: plant closing (-0.43 percent), slump in demand ( -0.58 percent), and other ( -0.48 percent). Those RIFs with missing reasons (956 of them) also have a significantly negative share price reaction of -0.45 percent. In contrast, the efficiency categories (reorganization and cost) show average excess returns that are positive and not significantly different from zero.

The evidence for whether a change in the composition of RIFs can account for the reduction in the negative share price effect is mixed. On the one hand, it does appear to be the case that 1) the composition of RIFs has shifted away from the deficient-demand categories and toward the efficiency category and 2) the average negative share price reaction in the deficient-demand categories is larger in magnitude than in the efficiency category. But it is also the case that the negative share price reaction within categories became 
smaller in magnitude in all categories but one (plant closing) between the 1970s and the 1990s.

\section{Within-Category Movements in the Distribution of Cumulative Excess Returns}

Given the heterogeneity in cumulative excess returns highlighted by the kernel density estimates in figures $5 \mathrm{a}$ and $5 \mathrm{~b}$, it is worth examining how the distributions of cumulative excess returns by reason have changed over time. To this end, figure 7a contains kernel density estimates of the distribution of cumulative excess returns by decade separately for the efficiency category of RIFs (reorganization and cost) and for the deficient demand category (demand slump and plant closing). The estimates for the efficiency categories in the first row of the figure show that there was a noticeable increase change in the distribution between the 1970-79 period and the later two decades. The right-hand panel highlights the center of the distribution and shows 1) that the density for negative values is higher in the 1970-79 period relative to later periods and 2) that the density for positive values is lower in the 1970-79 period relative to later periods. Thus, it appears that the the distribution of cumulative excess returns for efficiency RIFs has shifted upward. This is verified by the information about changes in these distributions over time is contained in figure $7 \mathrm{~b}$. Analogously to figure $5 \mathrm{~b}$, this figure contains plots of the three decadal differences (1980s - 1970s, 1990s - 1980s, and 1990s-1970s respectively by column) in the estimated density functions and cumulative distribution functions (CDFs) of the cumulative excess returns for efficiency RIFs. These plots show that most of the change occurred in the center of the distribtion, and, like the overall distribution, that the distribution for the later periods "almost" stochastically dominates the distributions for earlier periods. Thus, it appears that the distribution of cumulative excess returns for efficiency RIFs moved to the right between the 1970s and 1990s, but, in contrast to the changes in the overall distribution, most of the change occurred between the $1970 \mathrm{~s}$ and the $1980 \mathrm{~s}^{13}$

The patterns for deficient demand RIFs, contained in figure 7c, are not as clear, as there are not large movements in the distributions for this category over time. As before, most

13 The change in the fraction of efficiency RIFS with negative cumulative excess returns dropped about 8 percentage points between the 1970s and 1980s and dropped another 4 percentage points between the 1980 s and 1990 s. 
of the change is in the center of the distribution, although over a somewhat wider range. The distribution for the 1980s does appear to stochastically dominate the distribution for the 1970s, suggesting a modest move to the right of the distribution over this period. But there is no clear pattern between the 1980s and 1990s for deficient demand RIFs.

This analysis of movements in the distributions of cumulative excess returns by type of RIF shows that there was a substantial movement to the right in the distribution in at least the efficiency category. This is further evidence suggesting that changes in composition of RIFs cannot account for all of the movement in the overall distribution over time.

\section{Decomposition of Change in Average Cumulative Excess Returns}

In order to quantify how much of the decline in the negative share price effect can be accounted for by the shift in composition, we decompose the change in the average cumulative excess returns between the 1970-79 period and the 1990-97 period in two ways. First, we ask how much of the change over this period ( 0.54 percentage points, from -0.65 in the 1970-79 period to -0.11 in the $1990-97$ period) comes from each category. Algebraically, the overall change $(\Delta)$ is

$$
\Delta=\sum_{j}\left[P_{j 1} R_{j 1}-P_{j 0} R_{j 0}\right],
$$

where period 0 refers to the 1970-79 period, period 1 refers to the 1990-97 period, $j$ indexes categories, $P_{j t}$ is the fraction of RIF announcements in period $t$ that are of type $\mathrm{j}$, and $R_{j t}$ is the average share price reaction for RIF announcements of type $j$ in period $t$. The term in brackets is the contribution to the overall change due to changes in share and stock price reactions in category $j$. Table 5 contains the components of this decomposition along with contribution of each category (in the last column). It is unfortunately clear that fully 46.3 percent $(0.25 / 0.54)$ of the overall change is due to changes in the "missing" category, for which we cannot infer anything about the reason for the RIF. The remaining 53.7 percent is due to the reorganization, plant closing, demand slump, cost issues, and "other" categories.

If we assume that reorganization and cost represent the efficiency categories and that plant closing and demand slump represent the deficient demand categories, it is the case 
that changes in the efficiency category accounts for $29.6(0.16 / 0.54)$ percent of the overall change and changes in the deficient demand categories account for $14.8(0.08 / 0.54)$ percent of the overall change.

The second type of decomposition breaks the overall change into components due to 1) a change in the mix of categories and 2) changes in the average excess returns within categories. We compute two versions of the decomposition of $\Delta$ in equation 3 . The first is

$$
\Delta=\sum_{j}\left[R_{j 0}\left(P_{j 1}-P_{j 0}\right)\right]+\sum_{j}\left[P_{j 1}\left(R_{j 1}-R_{j 0}\right)\right]
$$

The first term of this decomposition is the contribution of the change in composition of the RIF announcements weighted by the average excess returns in the initial period (197079). The second term of the decomposition is the contribution of the change in returns within each category weighted by the proportion of RIFs of reason $j$ in the second period (1990-97). The second version of this decomposition is

$$
\Delta=\sum_{j}\left[R_{j 1}\left(P_{j 1}-P_{j 0}\right)\right]+\sum_{j}\left[P_{j 0}\left(R_{j 1}-R_{j 0}\right)\right]
$$

This is identical to the first decomposition except that 1) the contribution of the change in composition of the RIF announcements is weighted by the average excess returns in the second period (1990-97) rather than in the initial period and 2) the contribution of the change in returns within each category is weighted by the proportion of RIFs of reason $j$ in the initial period (1970-79) rather than in the second period.

Table 6 contains estimates of these two decompositions using the average returns and fraction of RIFs in each category listed in table 5 . These estimates suggest that changes in the distribution of RIFs by reason account for a relatively small fraction of the change in the share price reaction between the 1970s and the 1990s. Depending on which decomposition is used, the share accounted for by changes in the distribution of RIFs accounts for between -11 percent $(-0.06 / 0.54)$ and 33.3 percent $(0.18 / 0.54)$ of the change in the share price reaction. The largest contributors to this change comes from changes in the fraction of RIFs that come from plant closing and cost reasons. Those that are due to plant closing, a deficient-demand category with a large negative average share price effect, decreased 
from 31 percent (in the 1970-79 period) to 14 percent (in the 1990-97 period). Those attributable to cost issues increased from only 3 percent (in the 1970-79 period) to 14 percent (in the 1990-97 period). When weighted by the later period share price reaction (column 4 of table 6), the decline in the plant closing category accounts for more than half $(0.10 / 0.18)$ of the change in the overall share price reaction that is due to changes in the distribution of RIFs. When weighted by the initial period share price reaction (column 2 ), the plant closing and "missing" categories account equally for all of the change. ${ }^{14}$ It is worth noting that the increases in share in the reorganization category contributes little to the change in the share price reaction. ${ }^{15}$

The majority of the overall share price reaction is accounted for by changes in the average share price reaction within categories (between 65 percent $(0.35 / 0.54)$ and more than 100 percent (0.59/0.54)), depending on the decomposition. Most of this is concentrated in two categories: "cost issues" and "missing". These two categories had movements from substantial negative average share price reactions in the initial period to insignificant average share price reactions in the later period.

In our view this analysis does not provide much support for the view that the decline in the negative share price effect of announcements of RIFs is due to a shift away from deficient demand RIFs and toward efficiency RIFs. However, neither does this analysis rule out this explanation. A reasonably large fraction of the change over time appears to be in the "missing" category, and we know little about these RIFs.

\section{Other Characteristics of Announced RIFs}

Next we consider industry. Figure 8 presents a graphical representation of the distribution of RIFs by major industry group. We were able to identify the industry in 3360 or 87 percent of the cases. There are three major categories: mining, construction, and manufacturing (37.08 percent), transportation and utilities (50.65 percent), and other (12.27

14 The "missing" category has a declining share and a negative initial share price reaction overall.

15 In fact, weighting by the initial period share price reaction (column 2), the reorganization category contributes negatively to the postive increase in the share price reaction. This is because this category had increasing share but a negative average share price reaction in the initial period. 
percent). As is the case with the reason groupings, the distribution across these industry categories varies over time. Figure 8 shows that the two largest categories, mining, construction and manufacturing, as well as transportation and utilities, have shown significant variability over time. Mining, construction and manufacturing represented more than half of all RIFs during the early and late 1970s, dipped to 15.05 percent in 1990 and returned to roughly $1 / 3$ in the mid 1990s. Transport and utilities varied from as high as 63.10 percent in 1976 to a low of 34.78 percent in 1997. The "other" category is increasing over time, due mostly to increases in trade and in finance.

The third section of table 4 contains a breakdown of the cumulative average excess returns by major industry group. In this case over all years (1970-97), both major categories have significantly negative cumulative average excess returns: 1) mining, construction, and manufacturing $(-0.46$, s.e. $=0.10)$, and transportation and utilities $(-0.47$, s.e. $=0.10)$. In the case of industry groupings, however, only the transportation and utilities category exhibits the trend of less negative returns through the decades. One other category (not reported in the tables) is service which represents only 1.22 percent of all RIFs. Although services are not significant overall, they go from a very large and significant negative effect in the 1970 s $(-3.96$, s.e. $=1.59)$ to a very large and significant positive effect in the $1990 \mathrm{~s}$ $(3.41$, s.e. $=1.19)$.

Next, we consider firm size. It is reasonable to think that large firms may have different share price reactions at the time of layoff announcements. In order to investigate this, we categorize firms by market value (share price times the number of shares outstanding, collected from COMPUSTAT) within each year into four categories: bottom 25 percent, from 25th percentile to median, from the median to the 75th percentile, and in the top quarter. The fourth section of table 4 contains a breakdown of the cumulative average excess returns by size quartile. The results suggest that as firms get larger, the share price reaction becomes less negative. The differences in average excess returns between the top and bottom quartiles and between the third and bottom quartile are significantly positive at conventional levels ( $\mathrm{p}$-values $=0.0005$ and 0.005 respectively). This trend is strongest in the data from the 1970s alone (column 2), but it not so clear in the later periods.

It also may be the case that firms letting go a higher fraction of their workforce are more likely to see larger share price effects than firms that let go smaller fractions of workers. 
Unfortunately, we do not have complete information on the number of employees involved in the announced RIFs. These data are available in only 27 percent of the cases. The next section of table 4 contains a breakdown of the cumulative average excess returns by the fraction of workforce involved in the RIF, and no consistent pattern is apparent.

Finally, we present in table 4 the cumulative average excess returns broken down by whether the RIFs were known to be permanent or temporary. Once again, this information is available for only a small fraction of the sample (33 percent), and no consistent pattern emerges from this analysis.

\section{Multivariate Analysis of the Cumulative Excess Returns}

In this section, we regress the cumulative excess returns from the three-day window on layoff characteristics using the sample of 3878 announcements. In order to summarize the change over time in the average excess returns, each specification contains a linear time trend, and our discussion focuses on this variable.

Panel A of table 7 contains the weighted least squares estimates of the time trend from this regression for four specifications in order to investigate the role of the stated reason in accounting for the time trend. ${ }^{16}$ In the base model with no other controls, there is a significant coefficient on the time trend $(0.0230$, se $=0.0071)$ which is consistent with the upward trend in figure 3 . In column 2 of panel A panel, we repeat the analysis using only the observations for which we have reason information. The coefficient estimate on the time trend is very similar. Columns 3 and 4 of panel A, repeat the analysis controlling for the stated reason at two levels of aggregation. In both cases, the time trend is still positive and significant but somewhat smaller than in the model without the reason indicators. Thus, at best, the stated reason for the RIF can account for only a small fraction of the positive time trend in average excess returns.

In panels $B$ and $C$ of table 7 we present results of the same style analysis controlling for industry and firm size respectively. The industry controls have virtually no effect on

16 The regression is weighted by the inverse of the sampling variance of the average excess returns for each layoff anouncement. 
the time trend. Interestingly, use of the firm size controls appears to result in a somewhat larger time trend.

Finally in panel D of table 7, we include all reason, industry and size indicators in a single equation along with the time trend. The positive time trend in average cumulative excess returns is roughly unaffected by the inclusion of the full set of control variables.

Although we are interested in explaining the fact that the relationship between announced RIFs and stock prices has become less negative over time, this does not mean that we should be restricted to a linear time trend. Figure 9 is the natural extension of table 7 where we are less restrictive about the functional form of the timing. The first panel of figure 9 (labeled raw excess returns) is exactly the same as figure 3 . It is simply the average cumulative excess return from the three-day window for each year from 1970 though 1997. The figure also includes a linear time trend. The rest of the figures are similar except that they represent the average residuals by year from regressions with various specifications. For example, the top middle panel in figure 9 (labeled adjusted for reason) is created by first regressing the three day cumulative excess return for each RIF on the 17 reason indicators and then taking the average residuals from this regression by year and plotting them. The time trend plotted through them is somewhat flatter than in the raw excess return case. The top right panel does the same as the middle right panel except that, in the first stage, the regression is weighted by the inverse of the appropriate variances of the excess returns. The middle three panels of figure 9 and the bottom left panel do the same for controlling first for firm value and then for industry. The last panel includes all of the covariates, and its time trend has approximately the same slope as the the plot of the residuals adjusted only for reason. Thus, it appears that controlling for reason does account for some of the positive time trend in the average cumulative excess returns.

\section{Concluding Remarks}

There now is a growing body of work which documents that announcements of RIFs by large firms lead, on average, to small negative effects on stocks prices. We confirm this result using a very large sample of firms over 28 years. This sample period is roughly four 
times longer, and the sample contains about three times more announced RIFs, than any other study to date. By virtue of having information on so many RIFs over such a long time period, we are able to consider whether there has been a change in the relationship between share prices and announced RIFs over time.

We have several findings. First we show that although there has been an explosion recently in terms of the number of newspaper articles written about job loss, announced RIFs seem to follow the business cycle quite closely. We also show that the overall stock price reaction (as measured, for example, by average or median cumulative excess returns), which has always been small (less than 1 percent), is most negative earlier in the sample and has become less so over time. Additionally, the fraction of announcements of RIFs that are associated with negative stock price reactions has declined steadily over time. We go on to consider why this change has occurred. We investigate whether a shift in the composition of the announced reasons for RIFs, away from "deficient-demand" RIFs and toward "effficency" RIFs, could have accounted for the change. However, we find that this shift can account for only a small fraction of the decline in the negative average stock price effect, and most of the decline remains unexplained. 


\section{References}

Abowd, John, George Milkovich, and John Hannon, 1990. The Effects of Human Resource Management Decisions on Shareholder Value. Industrial and Labor Relations Review, February, 43(3), 203s-36s.

Anderson, Sarah and John Cavanagh, 1990. Workers Lose, CEOs Win. unpublished report, Institute for Policy Studies, Washington, D.C.

Blackwell, David, W. Wayne Marr, and Michael F. Spivey, 1990. Plant Closing Decisions and the Market Value of the Firm. Journal of Financial Economics, August, 26(2), $277-88$.

Brown, Stephen J. and Jerold B. Warner, 1985. "Using Daily Stock Returns: The Case of Event Studies. Journal of Financial Economics, March, 41(1), 2-31.

Campbell, John Y., Andrew W. Lo, and A. Craig MacKinlay, 1997. The Econometrics of Financial Markets, Princeton University Press.

Card, David, and Alan Krueger, 1995. Myth and Measurement: The New Economics of The Minimum Wage, Princeton University Press.

Caves, Richard E., and Matthew B. Krepps, 1993. Fat: The Displacement of Nonproduction Workers from U.S. Manufacturing Industries, Brookings Papers on Economic Activity, MicroEconomics, 2, 227-273.

Council of Economic Advisors, 1998, Economic Report of the President, United States Government Printing Office.

Datta, Sudip, and Mai Iskandar-Datta, 1996. A Financial Analysis of Corporate Downsizing: Evidence from Employee Layoffs, mimeo, Bentley College.

Dial, Jay and Murphy, Kevin J., 1995. Incentives, Downsizing, and Value Creation at General Dynamics. Journal of Financial Economics, 37, 261-314.

Fama, Eugene, Lawrence Fisher, Michael Jensen, and Richard Roll, 1969. The Adjustment of Stock Price to New Information. International Economic Review, February, 10(1), $1-21$.

Farber, Henry S., 1997. The Changing Face of Job Loss in the United States, 1981-1995. Brookings Papers on Economic Activity: Microeconomics. 
Gombola, Michael J. and Tsetsekos, George P., 1992. Plant Closings for Financially Weak and Financially Strong Firms. Quarterly Journal of Business and Economics, Summer, $31(1), 69-83$.

Gunderson, Morley, Anil Verma, and Savita Verma, 1997. Impact of Layoff Announcements on the Market Value of the Firm. Relations Industrielles/Industrial Relations, Spring, 52(2), 364-81.

Hallock, Kevin F., 1998. Layoffs, Top Executive Pay and Firm Performance. American Economic Review, September, 88(4), 711-23.

Jacoby, Sanford, 1998. Downsizing in the Past. Challenge, May-June, 41(3), 100-12.

Kalra, Rajiv, Glenn V. Henderson Jr., and Michael C. Walker, 1994. Share Price Reaction to Plant-Closing Announcements. Journal of Economics and Business, December 46(5), $381-95$.

MacKinlay, A. Craig, 1997. Event Studies in Economics and Finance. Journal of Economic Literature, March, 35(1), 13-39.

Sloan, Allan, 1996. The Hit Men. Newsweek, February 127(9), 44-48.

Thompson II, Robert B., Chris Olsen, and J. Richard Dietrich, 1987. Attributes of News About Firms: An Analysis of Firm-Specific News Reported in the Wall Street Journal Index. Journal of Accounting Research, 25(2), 245-74.

Ursel, Nancy, and Marjorie Armstrong-Stassen, 1995. The Impact of Layoff Announcements on Shareholders. Relations Industrielles/Industrial Relations, Summer, 50(3), $636-49$.

Worrell, Dan L., Wallace N. Davidson, and Varinder M. Sharma, 1991. Layoff Announcements and Stockholder Wealth. Academy of Management Journal, September 34(3), $662-78$. 
Table 1. Simple Characteristics of Sample Firms

Firms in the sample include all firms that ever existed in the Fortune 500 from 1970 through 1997. There are a total of 1176 unique firms. The data include 3878 job loss announcements collected from the Wall Street Journal Index for each of these firms from 1970 through 1997. The data in table 1 are from COMPUSTAT annual file and include firm value, assets, and sales in millions, and the number of employees in thousands for observations for which we have data from COMPUSTAT. The table is further broken down by all years, the 1970s, the 1980s, and the 1990s. Within each time period (for the financial variables) we report nominal and real (1997) dollars. We report the means within each category, standard deviations in parentheses, and medians in brackets.

\begin{tabular}{|c|c|c|c|c|c|c|c|c|}
\hline & \multicolumn{8}{|c|}{ Time Period } \\
\hline & \multicolumn{2}{|c|}{ 1970-1997 } & \multicolumn{2}{|c|}{$1970-1979$} & \multicolumn{2}{|c|}{ 1980-1989 } & \multicolumn{2}{|c|}{$1990-1997$} \\
\hline & nominal & real & nominal & real & nominal & real & nominal & real \\
\hline \multicolumn{9}{|c|}{ Financial in millions } \\
\hline \multirow[t]{4}{*}{ Firm Value } & 5447 & 8283 & 1891 & 6160 & 4872 & 7297 & 11823 & 13117 \\
\hline & $(10956)$ & (14408) & $(3368)$ & $(11036)$ & (9771) & $(14057)$ & $(16303)$ & (17999) \\
\hline & [1442] & [2892] & [624] & [1958] & {$[1565]$} & [2495] & {$[4767]$} & {$[5206]$} \\
\hline & \multicolumn{2}{|c|}{$N=3305$} & \multicolumn{2}{|c|}{$\mathrm{N}=1228$} & \multicolumn{2}{|c|}{$\mathrm{N}=1277$} & \multicolumn{2}{|c|}{$N=800$} \\
\hline \multirow[t]{4}{*}{ Assets } & 3054 & 5676 & 2003 & 6081 & 3475 & 5580 & 4478 & 4987 \\
\hline & $(5245)$ & $(8089)$ & $(2750)$ & $(7701)$ & $(4958)$ & $(7690)$ & $(8553)$ & $(9586)$ \\
\hline & [1090] & [2215] & [788] & [2521] & [1408] & [2230] & {$[1560]$} & {$[1701]$} \\
\hline & \multicolumn{2}{|c|}{$\mathrm{N}=2959$} & \multicolumn{2}{|c|}{$N=1223$} & \multicolumn{2}{|c|}{$\mathrm{N}=1183$} & \multicolumn{2}{|c|}{$\mathrm{N}=553$} \\
\hline \multirow[t]{4}{*}{ Sales } & 12704 & 20899 & 6317 & 18964 & 12925 & 20148 & 22145 & 25064 \\
\hline & (21183) & $(29875)$ & $(9532)$ & $(26484)$ & $(19404)$ & $(29112)$ & $(31014)$ & $(35150)$ \\
\hline & [3733] & {$[7228]$} & [2118] & {$[6637]$} & [4399] & [7064] & [8344] & [8988] \\
\hline & \multicolumn{2}{|c|}{$N=3306$} & \multicolumn{2}{|c|}{$N=1228$} & \multicolumn{2}{|c|}{$N=1227$} & \multicolumn{2}{|c|}{$\mathrm{N}=801$} \\
\hline \multicolumn{9}{|c|}{ Personnel in thousands } \\
\hline \multirow[t]{4}{*}{ Employees } & \multicolumn{2}{|c|}{106} & \multicolumn{2}{|c|}{122} & \multicolumn{2}{|c|}{98} & \multirow{4}{*}{\multicolumn{2}{|c|}{$\begin{array}{c}92 \\
(111) \\
{[43]} \\
N=800\end{array}$}} \\
\hline & \multirow{3}{*}{\multicolumn{2}{|c|}{$\begin{array}{c}(135) \\
{[43]} \\
N=3289\end{array}$}} & \multicolumn{2}{|c|}{$(153)$} & \multicolumn{2}{|c|}{ (129) } & & \\
\hline & & & & & \multicolumn{2}{|c|}{ [41] } & & \\
\hline & & & $N=$ & 1224 & $N=$ & 1265 & & \\
\hline
\end{tabular}


Table 2. Summary of Selected previous Studies and Comparison with new Data: Three-Day Event Window (day -1 to day +1 )

The first panel of table 2 reports results from ten previous papers which have examined the relationship between job loss announcements and stock prices. We have included the years the studies cover, the number of observations in each study, the specific focus of the study (e.g. Canadian firms only, plant closings only, etc.), and the three day average cumulative excess return in percent. The median of the previous studies is -0.5 . The third panel reports our overall estimate of the share price reaction to the 3878 job loss announcements in 1176 firms we collected from the Wall Street Journal Index. In the second panel, we report the cumulative average excess returns for our paper separately for the $1970 \mathrm{~s}$, 1980 s, and 1990s and document the less negative trend over time.

\begin{tabular}{|c|c|c|c|c|}
\hline Author(s) & $\begin{array}{l}\text { Years } \\
\text { Data } \\
\text { Cover }\end{array}$ & $\begin{array}{l}\text { Number of } \\
\text { Observations }\end{array}$ & Type of RIFs & $\begin{array}{c}\text { Average (\%) } \\
\text { Cumulative } \\
\text { Return }\end{array}$ \\
\hline A Abowd, et. al. (1990) & 1980,1987 & 87 and 38 & $\begin{array}{l}\text { Permanent } \\
\text { reductions }\end{array}$ & -0.6 and -0.2 \\
\hline B Blackwell, et. al. (1990) & $1980-1984$ & 286 & Plant closings & -0.7 \\
\hline C Caves \& Krepps (1993) & $1987-1991$ & 513 & $\begin{array}{l}\text { Manufacturing } \\
\text { firms only }\end{array}$ & -0.9 \\
\hline D Datta \& Iskandar-Datta (1996) & $1989-1991$ & 228 & Broad set & $-1.3^{(\mathrm{a})}$ \\
\hline E Golomba \& Tsetkekos (1992) & $1980-1986$ & 282 & Plant closings & -0.5 \\
\hline F Gunderson, et. al (1997) & $1982-1989$ & 214 & Canadian firms & -0.5 \\
\hline G Hallock (1998) & $1987-1995$ & 1287 & Broad Set & -0.3 \\
\hline H Kalra, et. al. (1994) & $1984-1987$ & 132 & Plant Closings & $-0.5^{(a)}$ \\
\hline $\begin{array}{l}\text { I Ursel \& Armstrong-Stassen } \\
\text { (1995) }\end{array}$ & 1989-1992 & 137 & Broad Set & $-0.6^{(\mathrm{b})}$ \\
\hline J Worell, et. al. (1991) & $1979-1987$ & 194 & Broad Set & -0.4 \\
\hline K Farber \& Hallock & $1970-1979$ & 1503 & Broad Set & -0.647 \\
\hline L Farber \& Hallock & $1980-1989$ & 1491 & Broad Set & -0.261 \\
\hline M Farber \& Hallock & $1990-1997$ & 884 & Broad Set & -0.112 \\
\hline Farber \& Hallock & $1970-1997$ & 3878 & Broad Set & -0.376 \\
\hline
\end{tabular}


TABLE 3. Frequencies of the Reported Reasons for the Announced RIFs

For the 3878 job loss announcements we collected from the Wall Street Journal Index in 1176 firms (each firm ever to appear in the Fortune 500 over our 28 year period) between 1970 and 1997, we also collected information on a variety of characteristics of the job loss announcements, including reported "reason" for the job loss. Reason is only available for 2922 ( 75 percent) of the 3878 announced RIFs. We also report frequencies and percent of the total of RIFs for each of the 17 RIF-types in the table.

\begin{tabular}{|c|c|c|}
\hline Reported Reason & Number & Percent \\
\hline Reorganization & 174 & 5.95 \\
\hline Restructuring & 170 & 5.82 \\
\hline Cost Control & 273 & 9.34 \\
\hline Slump in Demand in Economy & 464 & 15.88 \\
\hline Increased Competition & 30 & 1.03 \\
\hline Merger & 46 & 1.57 \\
\hline Restore Profitibility & 33 & 1.13 \\
\hline Bankruptcy & 4 & 0.14 \\
\hline Leaving Market & 23 & 0.79 \\
\hline In House Merger & 7 & 0.24 \\
\hline Posting Losses & 89 & 3.05 \\
\hline Plant Closing & 990 & 33.88 \\
\hline Increase Earnings & 5 & 0.17 \\
\hline Excess Supply & 132 & 4.52 \\
\hline Structural & 141 & 4.83 \\
\hline Strike & 138 & 4.72 \\
\hline Other & 203 & 6.95 \\
\hline
\end{tabular}


TABLE 4: Cumulative Average Excess Returns for Three-Day Event Window (day -1 to day +1 ) for selected sub-periods and by announced RIF characteristic

Cumulative average excess returns for the three days around the announcement of the job loss are reported for the entire time period, and for each of the three decades: 1970-1979, 1980-1989, and 19901997. We also report cumulative average excess returns by each of five reasons: reorganization (which includes categories reorganization, restructuring, merger, and in house merger), plant closing, demand slump, cost issues, other, as well as for the missing reason. In addition, we report cumulative average excess returns for the three day window for a set of industry groups, firm size (measured by market value within year) quartiles, the fraction of employees announced to be let go, and by whether the job loss is temporary or permanent. Standard errors are reported in parentheses. * indicates that the t-statistic for the cumulative average excess return being different than zero is greater than 2 .

\begin{tabular}{|c|c|c|c|c|c|}
\hline & & & Time & eriod & \\
\hline & $\mathrm{N}$ & $1970-1997$ & $1970-1979$ & $1980-1989$ & $1990-1997$ \\
\hline All RIFs & 3878 & $-0.38 *(0.06)$ & $-0.65 *(0.10)$ & $-0.26 *(0.10)$ & $-0.11(0.13)$ \\
\hline Reason & & & & & \\
\hline Reorganization & 397 & $0.07(0.19)$ & $-0.19(0.55)$ & $0.06(0.31)$ & $0.13(0.26)$ \\
\hline Plant Closing & 990 & $-0.43 *(0.12)$ & $-0.55^{*}(0.18)$ & $-0.23(0.18)$ & $-0.59(0.34)$ \\
\hline Demand Slump & 464 & $-0.58 *(0.18)$ & $-0.84 *(0.37)$ & $-0.39(0.26)$ & $-0.57(0.35)$ \\
\hline Cost Issues & 273 & $0.03(0.25)$ & $-1.60 *(0.56)$ & $0.20(0.47)$ & $0.52(0.34)$ \\
\hline Other & 798 & $-0.48 *(0.14)$ & $-0.49 *(0.20)$ & $-0.45(0.24)$ & $-0.47(0.29)$ \\
\hline Missing & 956 & $-0.45 *(0.12)$ & $-0.75 *(0.18)$ & $-0.37(0.21)$ & $0.15(0.30)$ \\
\hline Industry & & & & & \\
\hline Mining, Const., Manuf. & 1246 & $-0.46 *(0.10)$ & $-0.72 *(0.17)$ & $-0.25(0.16)$ & $-0.32(0.22)$ \\
\hline Transport. and Utilities & 1702 & $-0.47 *(0.10)$ & $-0.77 *(0.16)$ & $-0.38 *(0.16)$ & $-0.16(0.21)$ \\
\hline Other & 412 & $-0.03(0.17)$ & $-0.69(0.46)$ & $0.35(0.27)$ & $-0.03(0.23)$ \\
\hline Missing & 518 & $-0.14(0.18)$ & $-0.20(0.25)$ & $-0.33(0.30)$ & $0.60(0.48)$ \\
\hline Firm Size within Year & & & & & \\
\hline Bottom 25\% & 866 & $-0.79 *(0.18)$ & $-1.45^{*}(0.29)$ & $-0.20(0.28)$ & $-0.77^{*}(0.35)$ \\
\hline Next $25 \%$ & 835 & $-0.44 *(0.13)$ & $-0.94 *(0.22)$ & $-0.30(0.20)$ & $0.13(0.25)$ \\
\hline Next $25 \%$ & 876 & $-0.25 *(0.10)$ & $-0.37(0.19)$ & $-0.12(0.17)$ & $-0.29(0.22)$ \\
\hline Top 25\% & 728 & $-0.10(0.10)$ & $-0.10(0.14)$ & $-0.33(0.17)$ & $0.27(0.20)$ \\
\hline Missing & 573 & $-0.20(0.17)$ & $-0.25(0.24)$ & $-0.44(0.28)$ & $0.62(0.42)$ \\
\hline Frac. of Employees in RIF & & & & & \\
\hline Below Median & 538 & $-0.30 *(0.14)$ & $-0.54(0.38)$ & $-0.14(0.22)$ & $-0.35(0.20)$ \\
\hline Above Median & 523 & $-0.00(0.19)$ & $-1.21 *(0.50)$ & $0.45(0.33)$ & $-0.05(0.25)$ \\
\hline Missing & 2817 & $-0.46 *(0.07)$ & $-0.63 *(0.11)$ & $-0.40 *(0.12)$ & $0.04(0.20)$ \\
\hline Temporary vs. Permanent & & & & & \\
\hline Temporary & 374 & $-0.14(0.19)$ & $-0.77 *(0.33)$ & $-0.12(0.29)$ & $0.44(0.36)$ \\
\hline Permanent & 924 & $-0.30 *(0.12)$ & $0.08(0.31)$ & $-0.38(0.22)$ & $-0.32(0.17)$ \\
\hline Missing & 2580 & $-0.44 *(0.08)$ & $-0.69 *(0.11)$ & $-0.25 *(0.12)$ & $0.10(0.23)$ \\
\hline
\end{tabular}


TABLE 5: Contribution of RIF Categories to Overall Change in Share Price Reaction 1970-79 - 1990-97

\begin{tabular}{l|ccccc} 
Reasons & $\begin{array}{c}\text { Fraction } \\
(1970-79)\end{array}$ & $\begin{array}{c}\text { Ave. Return } \\
(1970-79)\end{array}$ & $\begin{array}{c}\text { Fraction } \\
(1990-97)\end{array}$ & $\begin{array}{c}\text { Ave. Return } \\
(1990-97)\end{array}$ & $\begin{array}{c}\text { Contribution } \\
\text { To Change }\end{array}$ \\
\hline Reorganization & 0.02 & -0.19 & 0.20 & 0.13 & 0.03 \\
Plant Closing & 0.31 & -0.55 & 0.14 & -0.59 & 0.09 \\
Demand Slump & 0.09 & -0.84 & 0.15 & -0.57 & -0.01 \\
Cost Issues & 0.03 & -1.60 & 0.14 & 0.52 & 0.13 \\
Other & 0.25 & -0.49 & 0.16 & -0.47 & 0.05 \\
Missing & 0.29 & -0.75 & 0.20 & 0.15 & 0.25 \\
\hline \multirow{2}{*}{ All } & 1.00 & -0.65 & 1.00 & -0.11 & 0.54
\end{tabular}

Note: Average cumulative excess returns are computed using three-day event windows. The "contribution to change" column contains the contribution to the overall change of 0.54 in the average cumulative excess returns due to the particular announced reason for each RIF. This is computed as $P_{j 1} R_{j 1}-P_{j 0} R_{j 0}$ for reason $j$, where period 0 refers to the $1970-79$ period, period 1 refers to the 1990-97 period, $P_{j t}$ is the fraction of RIF announcements in period $t$ that are of type $\mathrm{j}$, and $R_{j t}$ is the is average share price reaction for RIF announcements of type $j$ in period $t$. 
TABLE 6: Decomposition of Overall Change in Share Price Reaction

1970-79 - 1990-97

\begin{tabular}{l|c|cc|cc} 
& $(1)$ & $(2)$ & $(3)$ & $(4)$ & $(5)$ \\
Reason & $\Delta$ & $R_{j 0}\left(P_{j 1}-P_{j 0}\right)$ & $P_{j 1}\left(R_{j 1}-R_{j 0}\right)$ & $R_{j 1}\left(P_{j 1}-P_{j 0}\right)$ & $P_{j 0}\left(R_{j 1}-R_{j 0}\right)$ \\
\hline Reorganization & 0.03 & -0.03 & 0.07 & 0.02 & 0.01 \\
Plant Closing & 0.09 & 0.10 & -0.00 & 0.10 & -0.01 \\
Demand Slump & -0.01 & -0.05 & 0.04 & -0.03 & 0.02 \\
Cost Issues & 0.13 & -0.18 & 0.30 & 0.06 & 0.07 \\
Other & 0.05 & 0.04 & 0.00 & 0.04 & 0.00 \\
Missing & 0.25 & 0.07 & 0.18 & -0.01 & 0.26 \\
\hline All & 0.54 & -0.06 & 0.59 & 0.18 & 0.35
\end{tabular}

Note: Average cumulative excess returns are computed using three-day event windows. Column 1 contains the contribution to the change in average cumulative excess returns from RIF announcements by reason. Columns 2 and 3 contain the first decomposition of this change, defined in equation 4. Columns 4 and 5 contain the second decomposition of this change, defined in equation 5 . The shares and returns required to compute these decompositions are contained in table 5 . Period 0 refers to the 1970-79 period, period 1 refers to the 1990-97 period, $j$ indexes the announced reasons, $P_{j t}$ is the fraction of RIF announcements in period $t$ that are of type $\mathrm{j}$, and $R_{j t}$ is the is average share price reaction for RIF announcements of type $j$ in period $t$. 
TABLE 7. Cumulative Excess Returns and the Time Trend, with and without additional controls Dependent variable in each is cumulative excess return for three day window (day -1 to day +1 )

This table reports the results of 15 separate least squares regressions. The dependent variable in each is the cumulative excess return over three days $(-1,0$, and +1$)$. In panel $A$, column 1 , we regress the cumulative excess returns (there are 3878 observations, one for each of the job loss announcements) on a time trend. In column 2 , we repeat this regression for the sample for which there are no missing "reason" variables. Column three then controls for five reason indicators: reorganization, plant closing, demand slump, cost issues, and other. Column four controls for all 17 reason indicators described in table 3. Panel B repeats the analysis of the relationship between the three day cumulative excess returns and the time trend but controls for industry indicator variables. Panel $\mathrm{C}$ does it again with four firm size (measured by quartiles of the market value distribution within year) and panel $\mathrm{D}$ does the same controlling for reasons, industries, and size. Standard errors are reported in parentheses. ${ }^{* * *}$ represents significant at $0.01,{ }^{* *}$ at 0.05 , and $*$ at 0.10 .

Panel A. Cumulative Excess Returns, reasons controlled

\begin{tabular}{lcccc}
\hline & Full Sample & \multicolumn{3}{c}{ Sample for Which we have Reason Data } \\
\hline Time Trend & $0.0230^{* * *}$ & $0.0249^{* * *}$ & $0.0179^{*}$ & $0.0207^{* *}$ \\
& $(0.0071)$ & $(0.0084)$ & $(0.0089)$ & $(0.0095)$ \\
5 Reason Indicators & No & No & Yes & No \\
17 Reason Indicators & No & No & No & Yes \\
$\mathrm{R}^{2}$ & 0.0027 & 0.0030 & 0.0067 & 0.0127 \\
$\mathrm{~N}$ & 3878 & 2922 & 2922 & 2922 \\
\hline
\end{tabular}

Panel B. Cumulative Excess Returns, industry controlled

\begin{tabular}{lcccc}
\hline & Full Sample & \multicolumn{3}{c}{ Sample for Which we have Industry Data } \\
\hline Time Trend & $0.0230^{* * *}$ & $0.0231^{* * *}$ & $0.0214^{* * *}$ & $0.0220^{* *}$ \\
& $(0.0071)$ & $(0.0076)$ & $(0.0079)$ & $(0.0079)$ \\
3 Industry Indicators & No & No & Yes & No \\
9 industry Indicators & No & No & No & Yes \\
$\mathrm{R}^{2}$ & 0.0027 & 0.0028 & 0.0030 & 0.0055 \\
$\mathrm{~N}$ & 3878 & 3360 & 3360 & 3360 \\
\hline
\end{tabular}

Panel C. Cumulative Excess Returns, size groups controlled

\begin{tabular}{lccc}
\hline & Full Sample & Sample for Which we have Complete Size Data \\
\hline Time Trend & $0.0230^{* * *}$ & $0.0229^{* * *}$ & $0.0345^{* * *}$ \\
& $(0.0071)$ & $(0.0076)$ & $(0.0077)$ \\
four size indicators & No & No & Yes \\
$\mathrm{R}^{2}$ & 0.0027 & 0.0027 & 0.0055 \\
$\mathrm{~N}$ & 3878 & 3305 & 3305 \\
\hline
\end{tabular}

Panel D. Cumulative Excess Returns, reasons, industry and size controlled

\begin{tabular}{lcccc}
\hline & Full Sample & \multicolumn{3}{c}{ Also have reason, industry, size controls } \\
\hline Time Trend & $0.0230^{* *}$ & $0.0269^{* * *}$ & $0.0201^{* *}$ & $0.0221^{* *}$ \\
& $(0.0071)$ & $(0.0091)$ & $(0.0099)$ & $(0.0102)$ \\
5 reas, 3 inds, 4 size indic. & No & No & Yes & No \\
17 reas, 9 inds, 4 size indc. & No & No & No & Yes \\
$\mathrm{R}^{2}$ & 0.0027 & 0.0035 & 0.0103 & 0.0190 \\
$\mathrm{~N}$ & 3878 & 2487 & 2533 & 2533 \\
\hline
\end{tabular}


Figure Captions for

Have Employment Reductions Become Good News for Shareholders? The Effect of Job Loss Announcements on Stock Prices, 1970-97

Figure 1.

Plot of the number of Wall Street Journal abstracts from 1985 through 1995 with the following words or word combinations: "layoff," "laid off," downsize," "plant closing," or downsizing." The data were collected from Pro Quest's Newspaper Abstracts. These articles need not relate to any specific firm. We do not use these data or this method of data collection elsewhere in the paper.

Figure 2.

Firms in the sample include all firms that ever existed in the Fortune 500 from 1970 through 1997. There are a total of 1176 unique firms. The data include 3878 job loss announcements collected from the Wall Street Journal Index for each of these firms from 1970 through 1997. The figure plots the frequency of job loss announcements each year from 1970 through 1997 on the left axis and the civilian unemployment rate on the right axis.

Figure 3.

This is a plot, by year, of the mean three day cumulative excess returns using our data of 3878 job loss announcements from 1176 firms (each firm to ever exist in the Fortune 500 from 1970 - 1997) for the 28 years from $1970-1997$. We have also graphically represented the results of ten earlier studies marked $\mathrm{A}-\mathrm{J}$ (see table 2 for a description of each of these studies). The horizontal span of the lines represents the years the previous studies covered and the vertical location represents the mean cumulative excess returns over the three day window. We also plot our decadal averages of the cumulative excess returns computed from our data with dotted lines (marked K-M for the 1970s, 1980s and 1990s respectively).

Figure 4.

These are plots by year which summarize the excess returns and cumulative excess returns from our data of 3878 job loss announcements from 1176 firms (each firm to ever exist in the Fortune 500 from 1970 - 1997) for the 28 years from 1970 - 1997. The first row represents the 1 day window (day 0 ), the second row represents cumulative excess returns over the three day window (day -1 to day +1 ) and the bottom row represents cumulative excess returns over the 11 day window (day -5 to day +5 ). The first column represents mean returns, the second column represents median returns and the third column represents the fraction negative. We have also plotted a linear time trend in each figure. The figure in the first column and second row is the same as the basic part of figure 3 . 
Figure 5a.

The first of these figures is a kernel density estimate of the distribution of all 3878 cumulative excess returns for the three day window by decade for the entire support of the distribution from roughly -0.4 to +0.4 . The other two figures focus only on the center of the distribution (from -0.2 to +0.2 and from -0.1 to +0.1 respectively). We used the Epanechnikov Kernel with a bandwidth of 0.006 . Various alterations to the bandwidth do not alter the figures in any meaningful way.

Figure 5b.

The first row of the figure represents plots of the three decadal differences (1980s $1970 \mathrm{~s}, 1990 \mathrm{~s}-1980 \mathrm{~s}$, and 1990s - 1970s, respectively by column) in the estimated density functions (from figure 5a). The second row represents the corresponding cumulative distribution functions (CDFs) of the cumulative excess returns. Negative (positive) values in these plots imply a smaller (larger) density or lower (higher) cumulative probability in the later period.

Figure 6.

The 17 reasons for job loss announcements (described in Table 3) are consolidated into five categories here: reorganization (which includes reorganization, restructuring, merger, and in house merger), plant closing, slump in demand, cost issues, and other, plus the missing category. One quarter of the 3878 observations have missing reason. We have plotted the relative frequencies of each of these categories, plus the missing category by year.

Figure 7a.

This figure contains kernel density estimates of the distribution of cumulative excess returns by decade separately for the efficiency category (reorganization and cost) and the deficient demand category (demand slump and plant closing). The left column plots the entire distribution in each case and right panel focuses on the center of the distribution. We used the Epanechnikov Kernel with a bandwidth of 0.006 .

Figure $7 b$.

This represents changes in the distributions from the top row of figure $7 \mathrm{a}$ (efficiency announcements) and contains plots of the three decadal differences (1980s - 1970s, 1990s 1980 s, and 1990s - 1970s, respectively by column) in the estimated density functions (top row) and cumulative distribution functions (CDFs) (bottom row) of the cumulative excess returns over the three day window. 
Figure $7 \mathrm{c}$.

This represents changes in the distributions from the top row of figure $7 \mathrm{a}$ (deficient demand announcements) and contains plots of the three decadal differences $(1980 \mathrm{~s}-1970 \mathrm{~s}$, $1990 s-1980 s$, and 1990s - 1970s, respectively by column) in the estimated density functions (top row) and cumulative distribution functions (CDFs) (bottom row) of the cumulative excess returns over the three day window.

Figure 8.

We have plotted the relative frequencies by year of each of the three main industry categories. The three categories are: 1) mining, construction and manufacturing, 2) transportation and utilities, and 3 ) other industries.

Figure 9.

The first panel in the figure (labeled raw excess returns) is the average cumulative excess returns for the three day $(-1$ to +1$)$ by year and is exactly the same as figure 3 . All figures also contain linear time trends. The rest of the figures are similar except that they represent the average residuals by year from regressions with various specifications. For example, the top middle panel is created by first regressing the three day cumulative excess return for each RIF on the 17 reason indicators and then taking the average residuals from this regression by year and plotting them. The top right panel does the same except that, in the first stage, the regression is weighted by the inverse of the appropriate variances of the excess returns. The rest of the figures are from similar analyses controlling for firm value, industry and finally reason, industry, and value. 


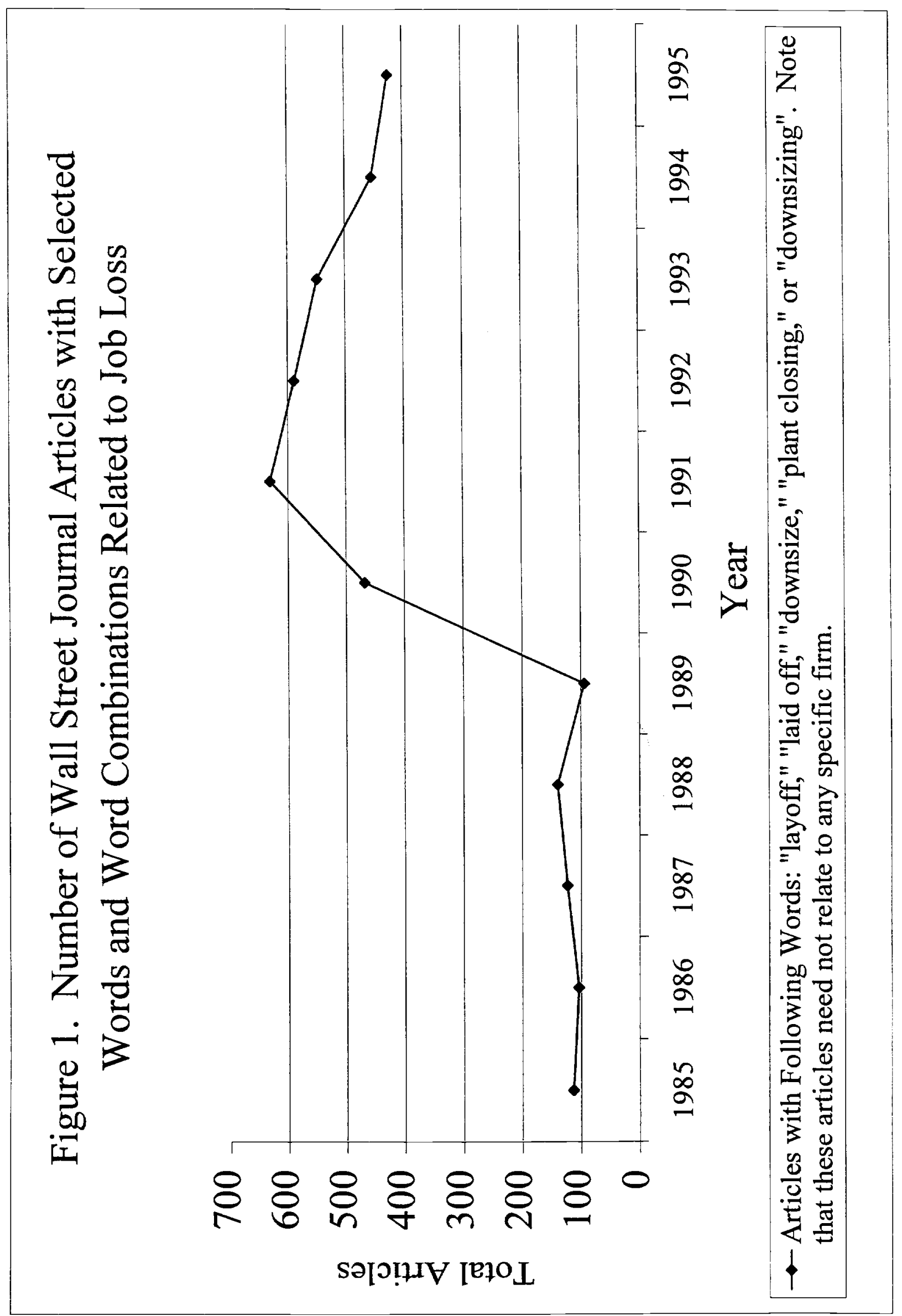




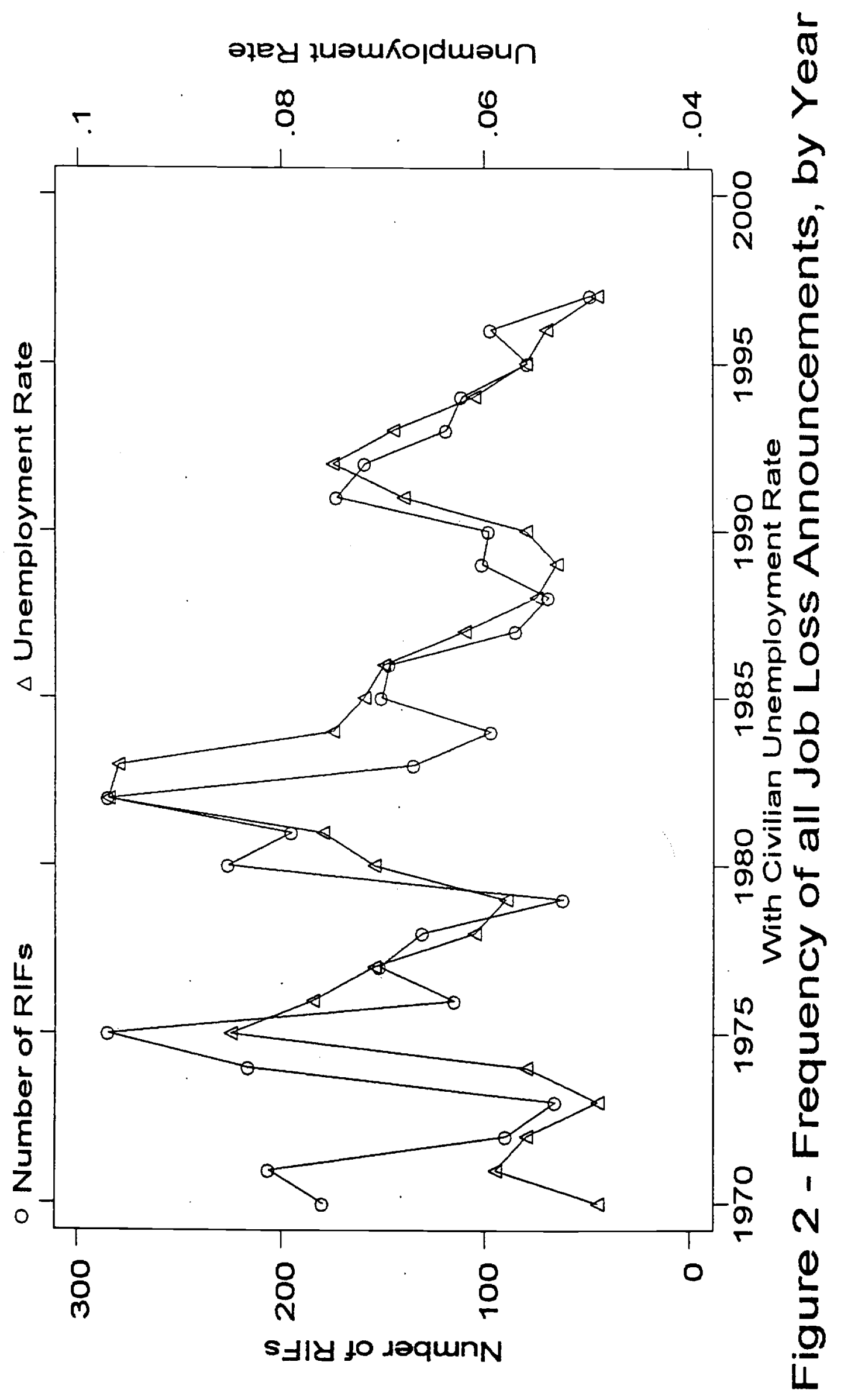




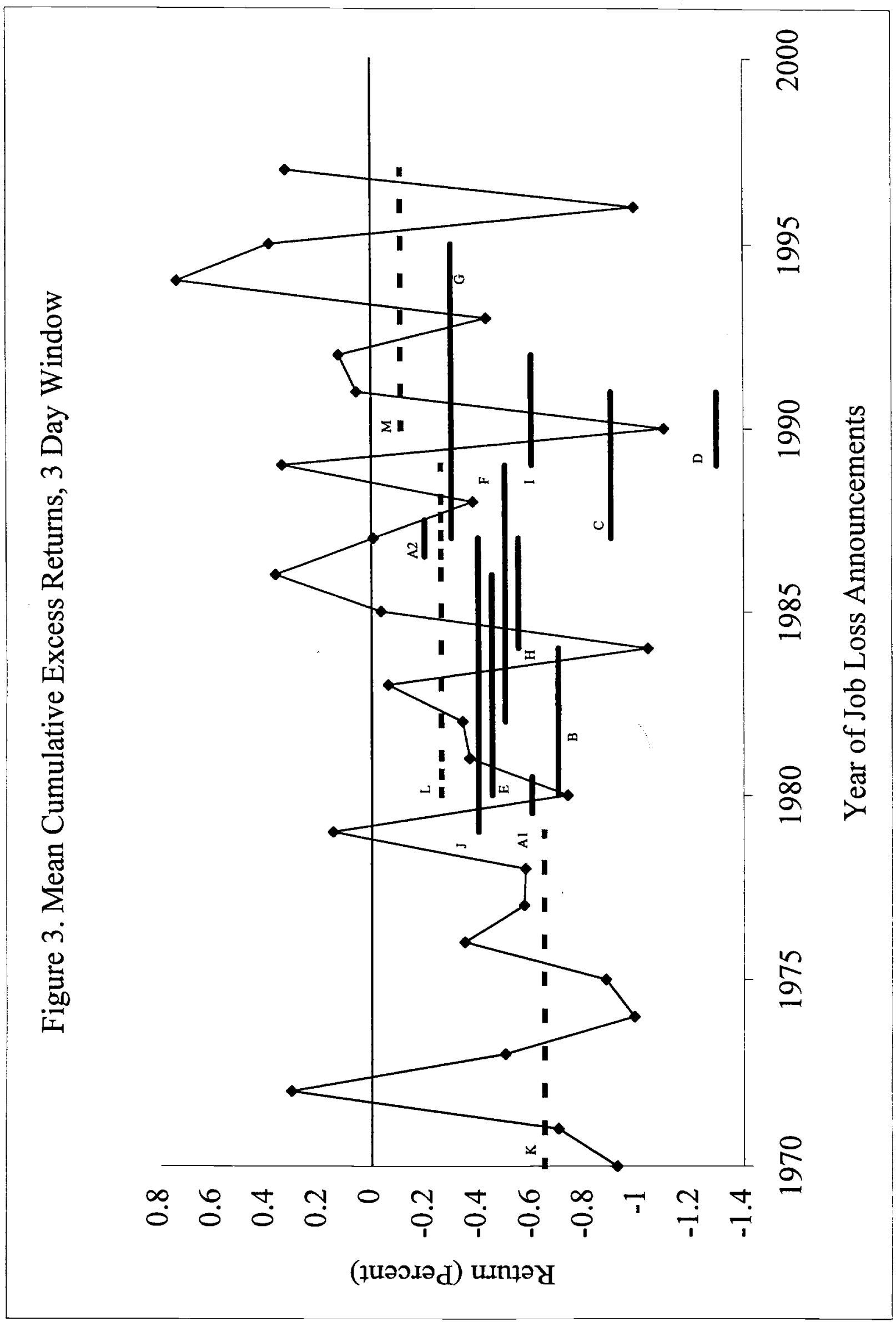




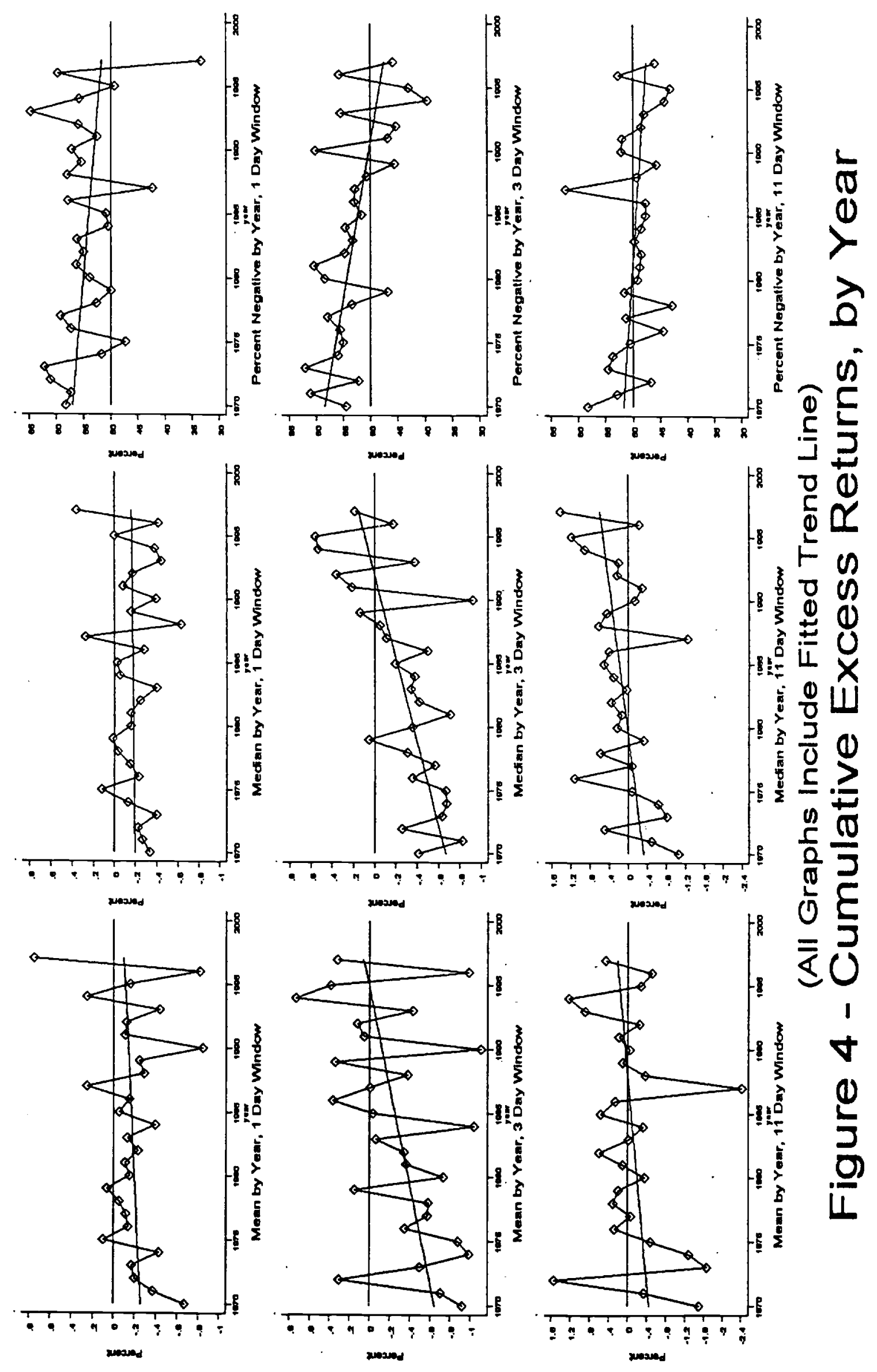




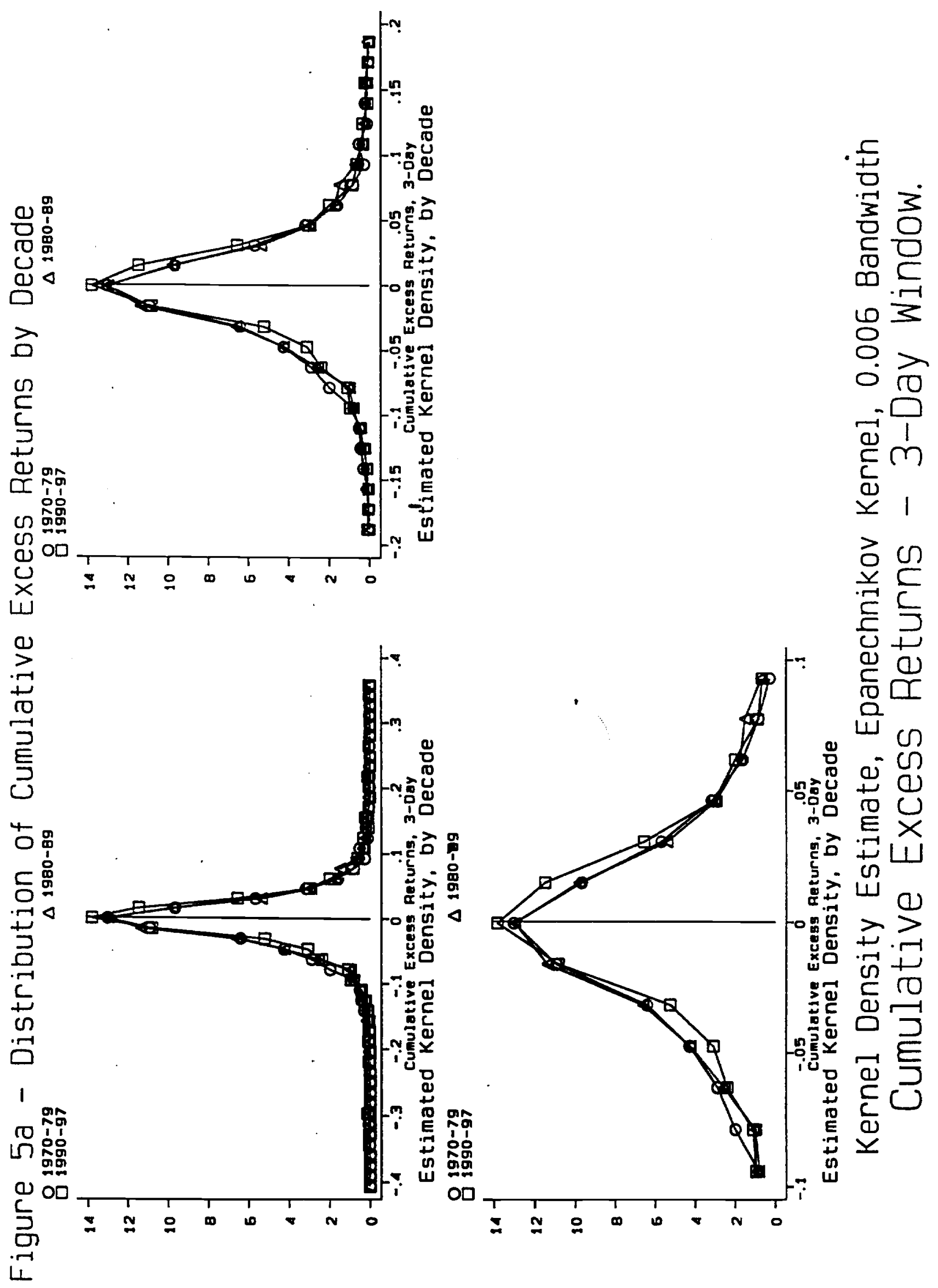




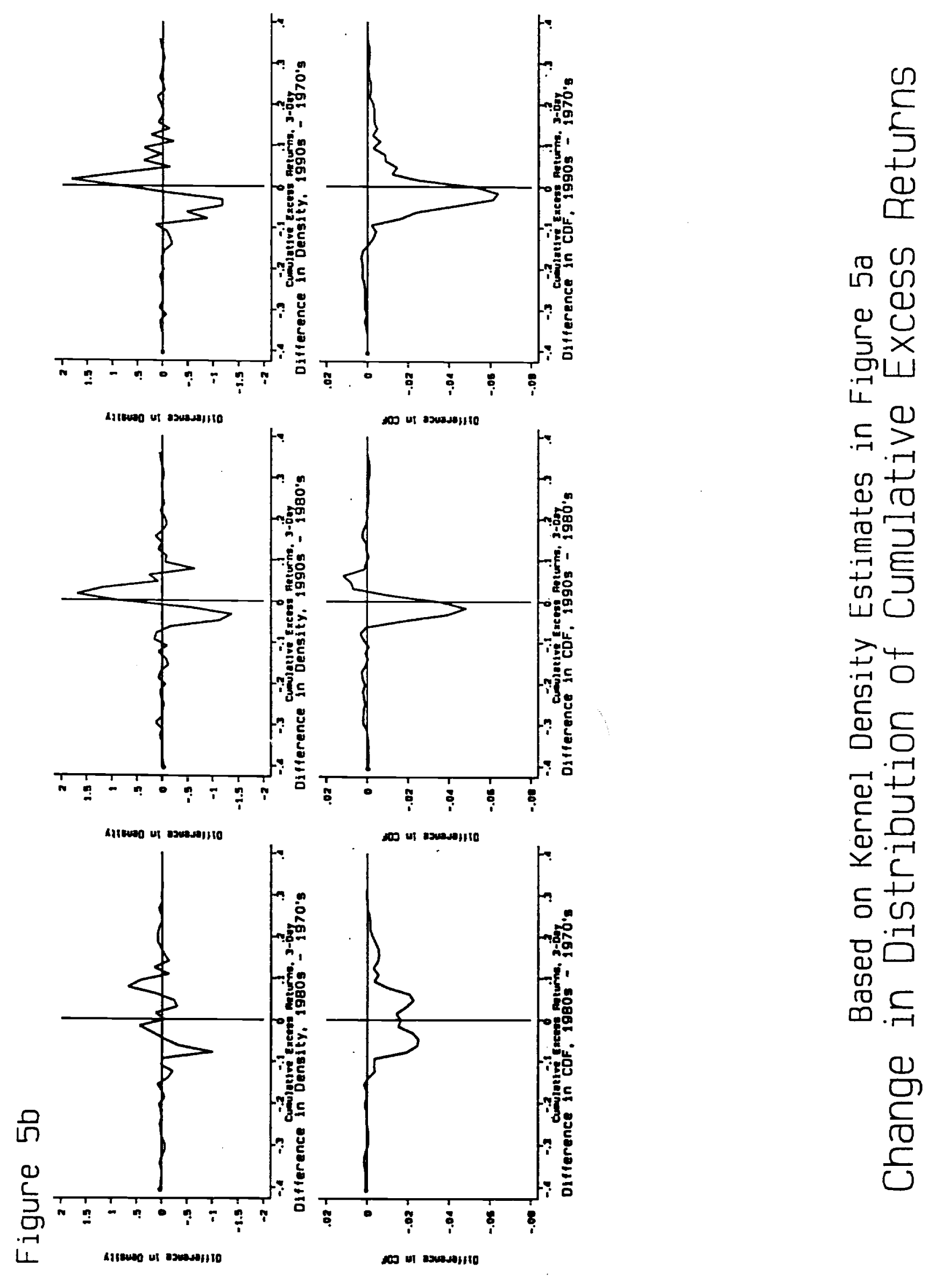



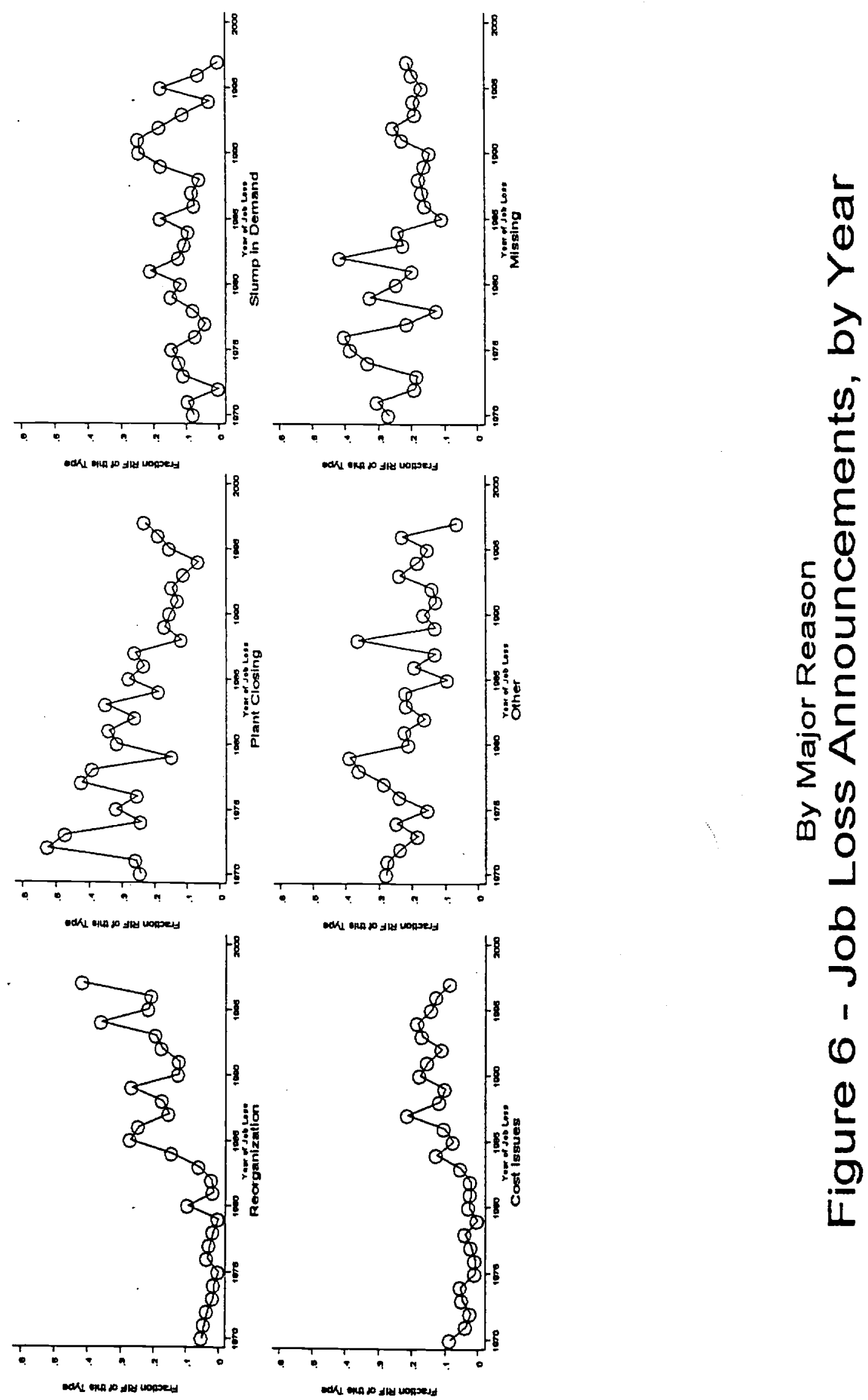


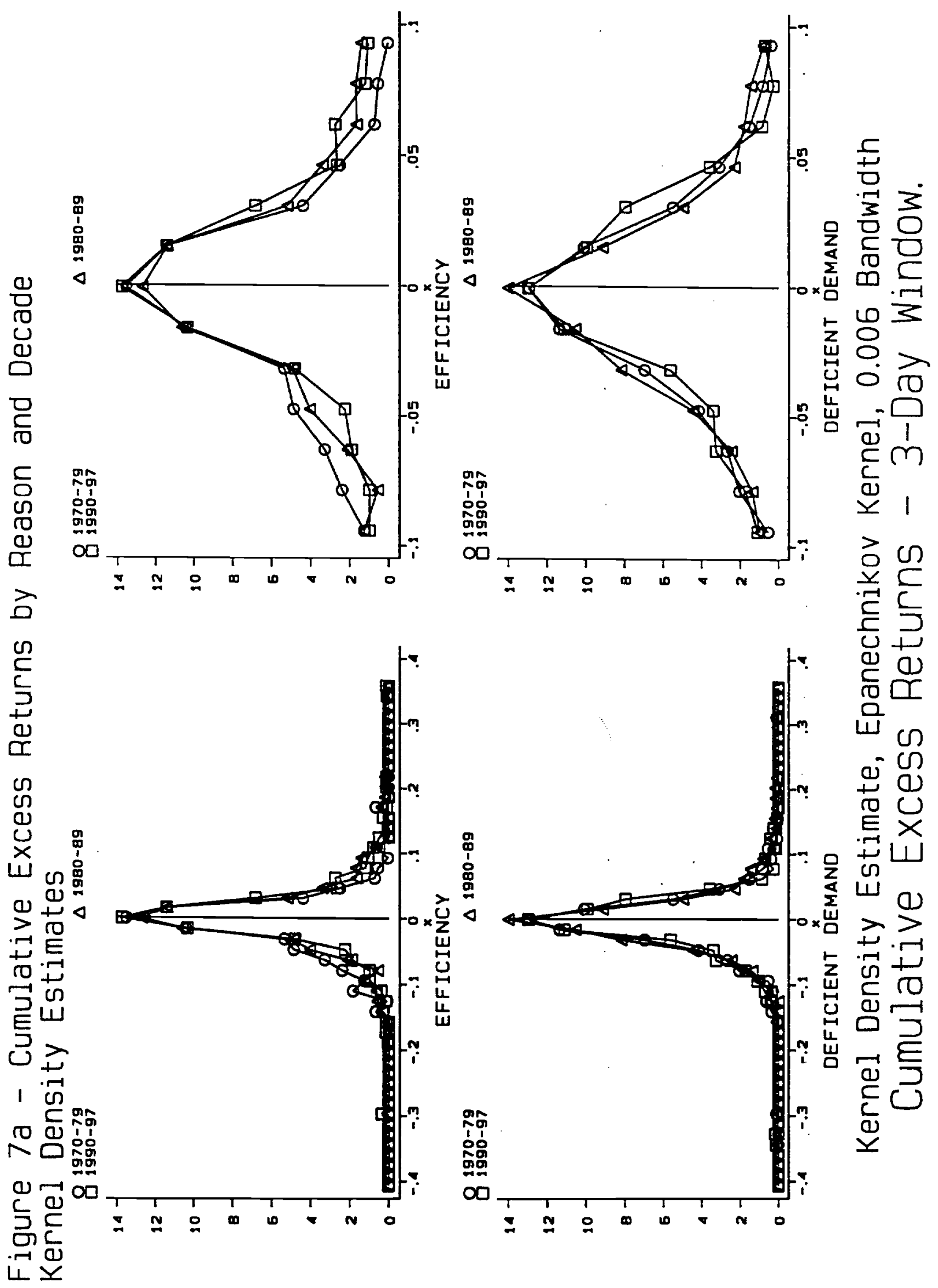




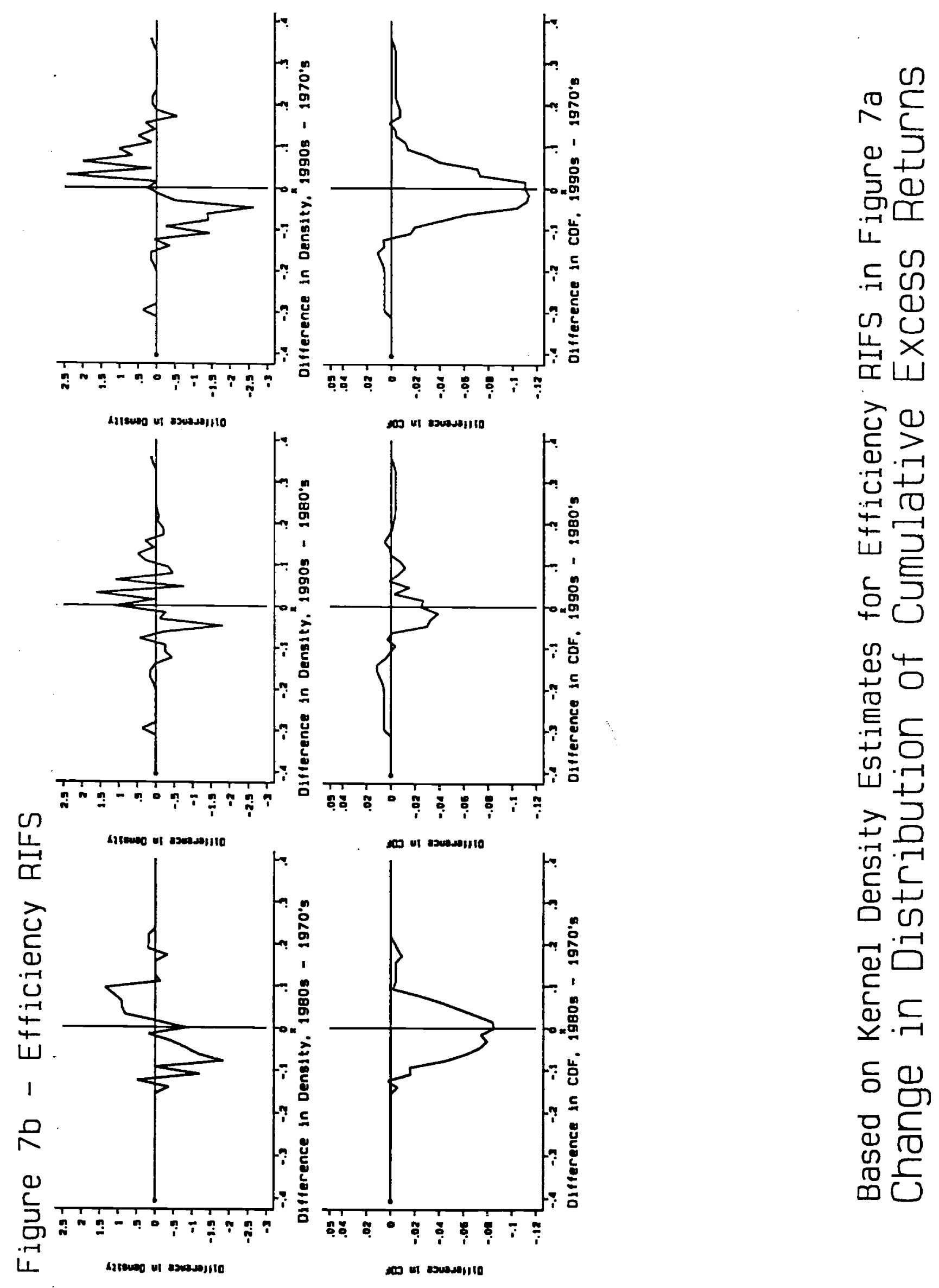




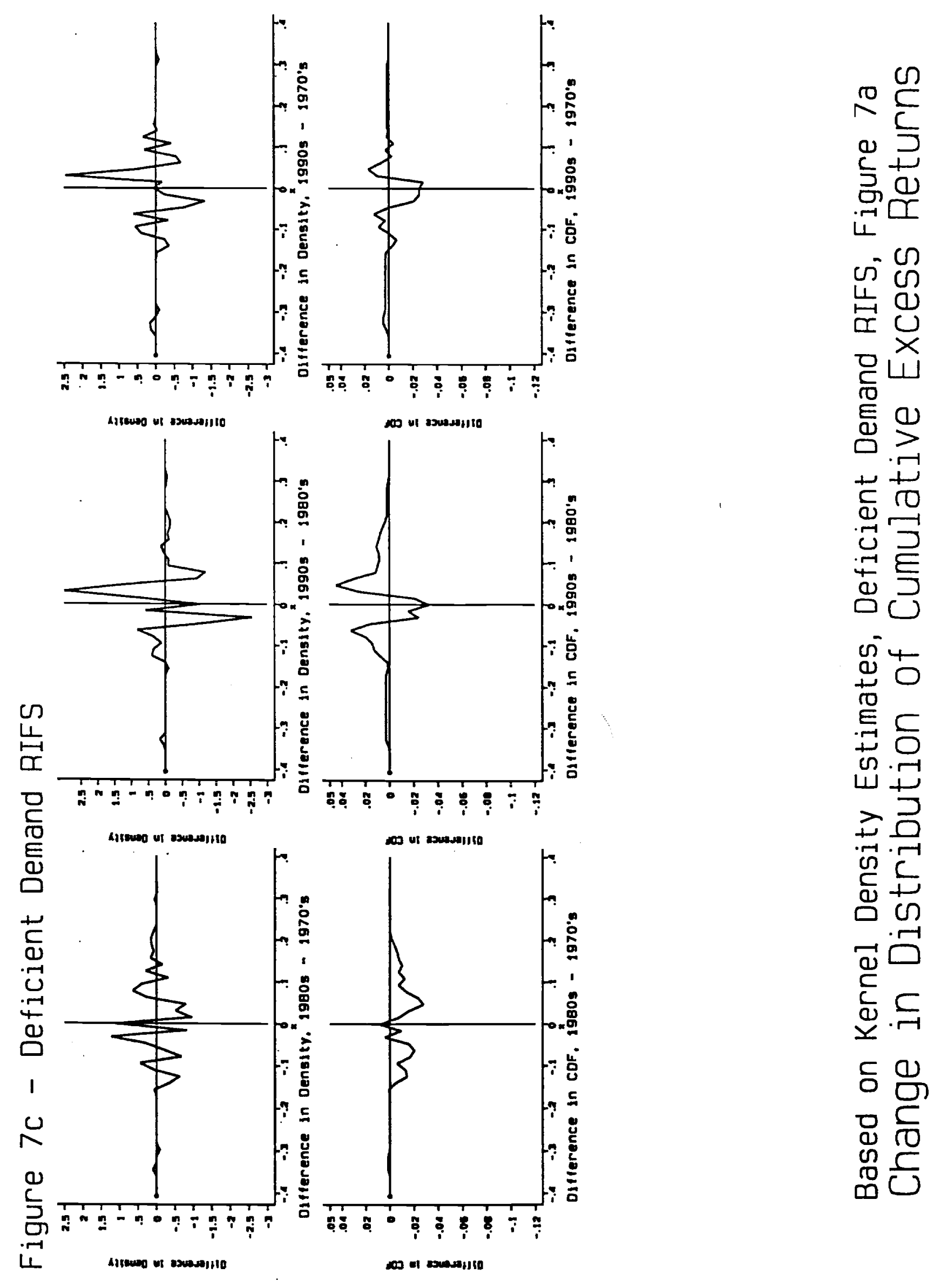



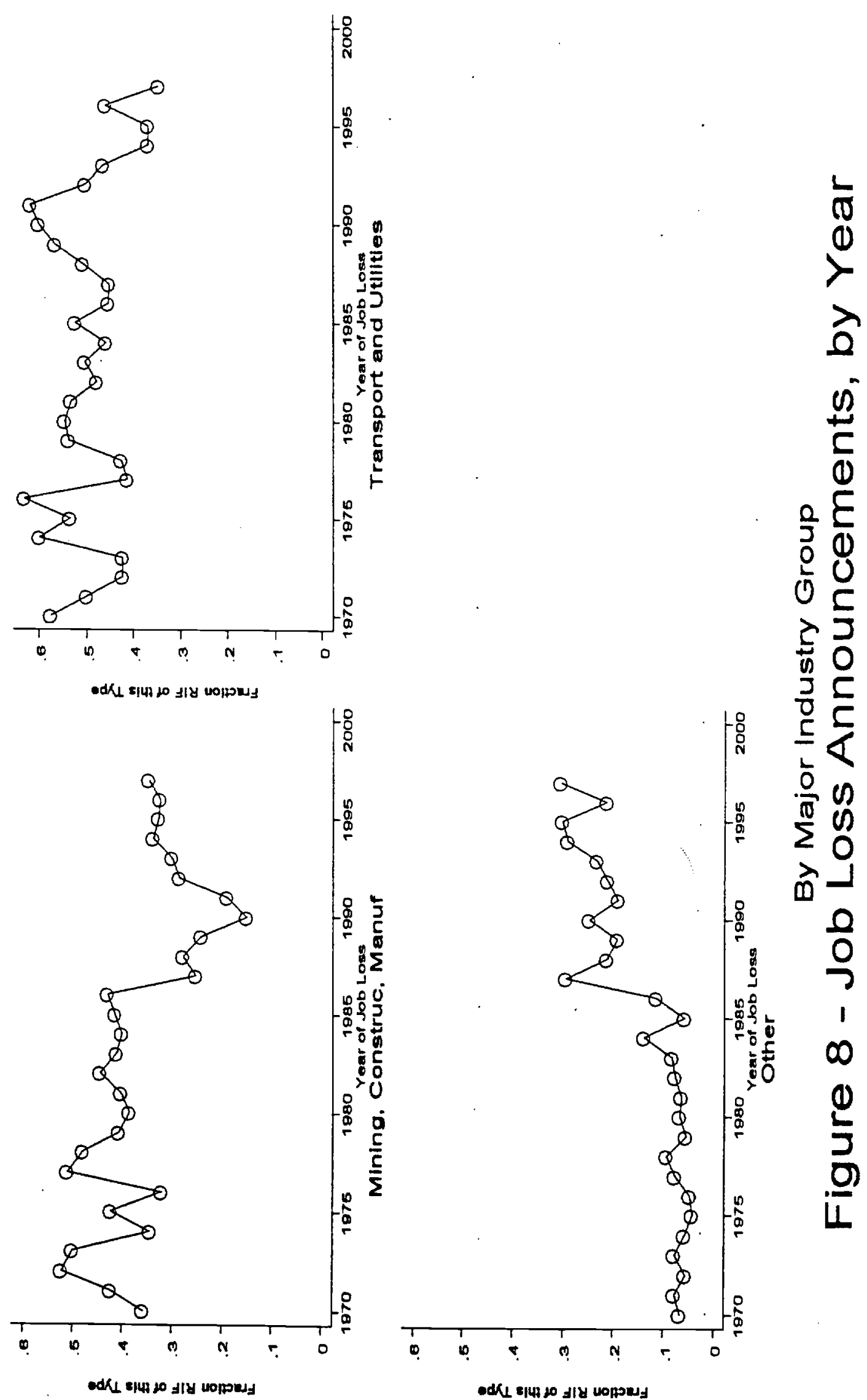

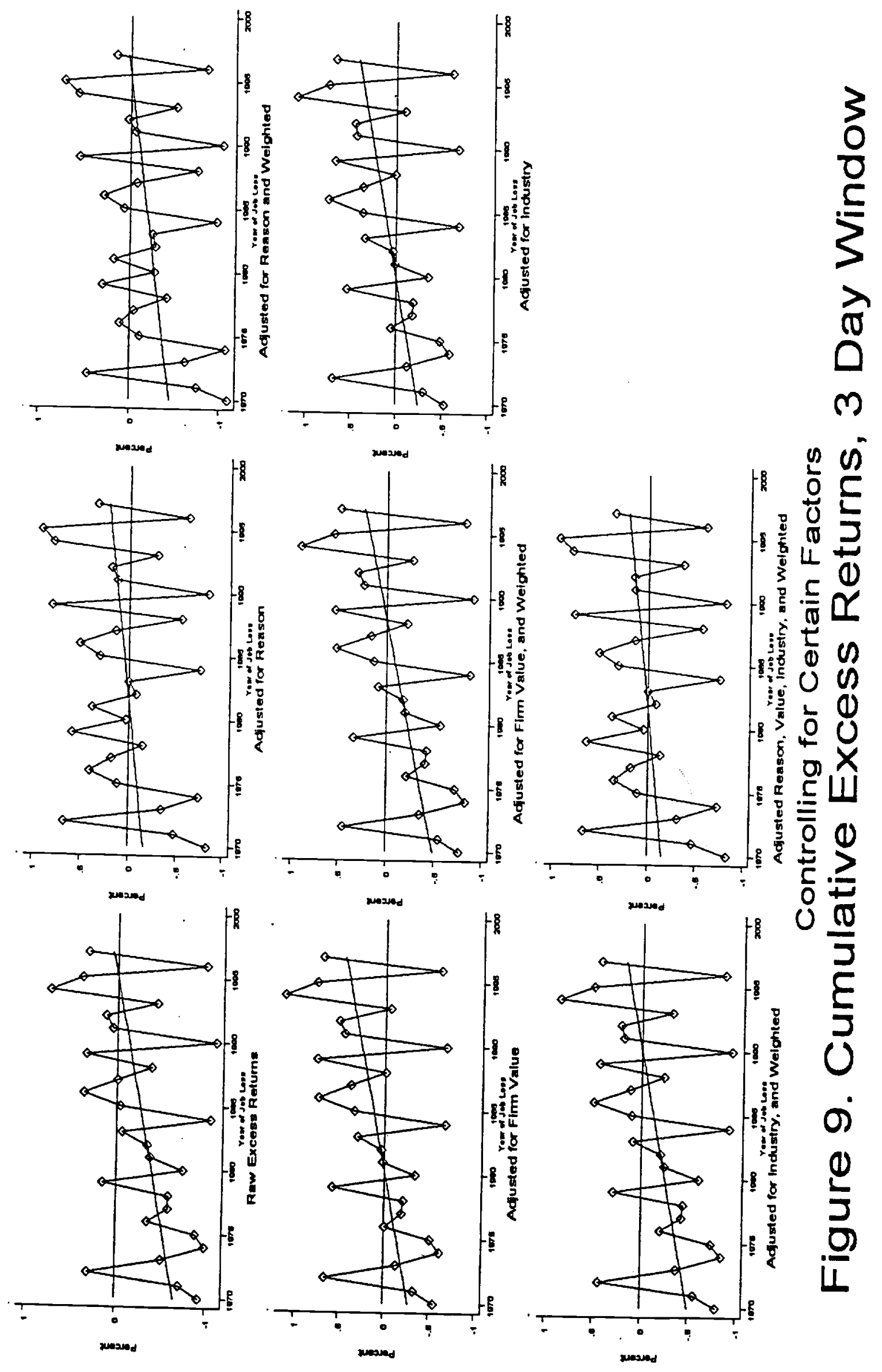